\title{
A study of transient effect of constant indirect flow velocity through multiple upper-vents in un-stratified rectangular ventilated building using theoretical approach
}

\author{
Muhammad Auwal Lawan ${ }^{1 *}$, Sunusi Aminu Nata Ala², Muhammad Yusuf Muhammad ${ }^{4}$, Aliyu \\ Lawan Musa $^{3}$, Rabi'u Bashir Yunusa ${ }^{4}$ and Bashir Danladi Garba ${ }^{4}$ \\ Senior Lecturer, Department of Mathematics, Kano University of Science and Technology, Nigeria ${ }^{1}$ \\ Researcher, Department of Mathematics, Kano University of Science and Technology, Wudil (KUST), Nigeria ${ }^{2}$ \\ Researcher, Department of Computer Engineering Technology, Ahmadu Bello University (ABU), Zaria, Nigeria ${ }^{3}$ \\ Lecturer, Department of Mathematics, Kano University of Science and Technology, Nigeria ${ }^{4}$
}

Received: 07-February-2020; Revised: 20-March-2020; Accepted: 24-March-2020

(C)2020 Muhammad Auwal Lawan et al. This is an open access article distributed under the Creative Commons Attribution (CC BY) License, which permits unrestricted use, distribution, and reproduction in any medium, provided the original work is properly cited.

\begin{abstract}
The paper is an extension of authors own work in which, studied of transient effect of stack-driven airflow in crossventilated building with three opening in the presence of opposing flow in one of the upper-vent. An analysis has been carried out to study the transient effect of constant indirect flow velocity in rectangular building with multiple uppervents induced by stack-driven effect. Moreover, equations of momentum and energy are non dimensionalised using some dimensionless quantities and solved theoretically by means of separation of variable method. The asymptotic behavior of parameters involved in the study predicts the result for Velocity, temperature distributions together with volumetric and mass- transfer. The results of the study are presented graphically and discussed for varying values of physical parameters involved such as, effective thermal coefficient $\left(\theta_{0}\right)$, Prandtl number $(P r)$ and Grashof number( Gr). In addition, comparison with previously published work by was performed. In which, the study concluded that, the results for present work is more effective and efficient than the previous work in term of ventilation process. Finally, from the course of investigation, it was observed air temperature and velocity increase with the increase in both parameters $\left(\theta_{0}\right),(P r)$ and ( Gr) respectively.
\end{abstract}

\section{Keywords}

Transient effect, Indirect flow velocity, Multiple upper vents, Ventilated building.

\section{Introduction}

Studied associated to natural convection flow of incompressible and compressible fluids has received considerable interest due to the enormous applications in various fields of industry, architectural design, science and technology. Several studies have been reported on natural convection flow under different physical situations. A study of natural ventilations in building plays an important role in architectural design especially, in building envelopes. Airflow process can either be achieved by natural means (natural ventilation) or by some external means such as, fan, air conditioners etc. (mechanical ventilation) or by combined natural and mechanical ventilations (hybrid ventilation).

*Author for correspondence
Many investigation and experiments have been carried out by previous researchers in ventilation phenomena. Some of the previous interventions in the area are; [1] investigated airflow process in single-sided building. Performed an experiment on scale effect in room air-flow and later [2, 3] investigated air movement on naturally-ventilated building. Investigated air flow across wall vents caused by thermal source in building based on the study given by $[4,3]$.

Studied the effect of buoyancy forces on airflow across the two openings in building [5]. Studied the effect of indirect flow with constant indirect velocity in rectangular ventilated building with three- vents [6]. Studied a building with bi-directional flow openings [7]. Developed a computational fluid dynamical model in rooms with indoor air pollutant 
[8]. Investigated a room airflow distribution system using computational fluid dynamic (CFD) [9]. Described the approach with advantages and disadvantages of various methods for modeling air flow in the building and also studies buoyancy-driven natural ventilation of buildings-impact of computational domain [10]. Studied displacement ventilation when the interior of the building was stratified[11]. Studied the mixed ventilation when the interior of the building has uniform temperature [12]. Considered airflow process combining the ideas of mixed and displacement ventilations in building by $[13,14]$. Studied effect of stack- driven airflow in cross- ventilated building with an opposing flow in one of the upper- vent [15]. Developed a mathematical modeling of wind forces [16].

Developed a linear thermal models of mixed- mode building [17]. Examined airflow process induced by buoyancy- driven forces on the floor of an enclosure in the presence of wind [18]. Estimated exchange of air by natural means potential and considered thermal comfort issues [19]. Performed an experiment examining the heat-transfer and airflow in interactive building façade [20]. Studied natural convection flow for heat and mass- transfer in a single- sided ventilated building [21]. Performed CFD simulation to reproduce the decay of $\mathrm{CO}_{2}$ concentration in a large semi-enclosed stadium [22]. Developed natural Ventilation potential model of airflow in china [23]. performed an experiment in heated, sealed room of a test house [24].

Performed an experiment on a vertical temperature distribution by combining natural and mechanical ventilation in an atrium building[25]. Performed an experiment and investigated effect of buoyancydriven forces in single- sided ventilated building with large openings by means of CFD methods[26]. Performed an experiment in full size ventilated box [27]. Studied a building with two openings at different vertical height [28]. Studied airflow caused by wind and buoyancy forces [29]. Studied the effect of wind- driven flow only in building interacted with wind [30]. Studied the effect of wind-driven flow in building envelope with small openings [31]. Developed a model of airflow induced by stackdriven effect in multi-compartment buildings. Calculation of heat- transfer and energy balance of a double skin façade (DSF) was studied by [32, 33]. Effect of two buoyancy forces on natural ventilation in an enclosure was investigated by [34]. Studied a natural convection flow in a single sided building with partition-I [35]. Studied a natural convection flow in a single sided building with partition-II [36]. Studied fluid mechanics of natural ventilation[37]. Performed an experiment in a full- scale naturally ventilated building [38]. Studied transient investigation of airflow through two upper verticalvents in the absence of constant indirect flow velocity in rectangular building [39]. Investigated the potential use of natural ventilation strategies in highrise building in summer [40]. Developed a nodal model to estimate temperature stratification in rooms with displacement ventilation [41]. Discussed numerical simulation of the wind velocity in individual building using multi- zone modelling [42]. Studied the impact of window parameters on the building [43].

The objectives of this study is presents the model and discuss the effect of parameters and other operating conditions involved in the study to the effect of constant indirect flow velocity in rectangular building with multiple- upper vents induced by stack- driven effect. The governing equations describing the flow are written in dimensionless form and solved theoretically by means of separation of variable method. In this paper the velocity, temperature distributions together with mass- transfer and volumetric airflow are obtained and discussed for some selected values of parameters, such as Effective thermal coefficient $\left(\theta_{0}\right)$, Prandtl number $(P r)$ and Grashof number $(G r)$. Therefore, the model is only limited with vertical openings on the same height.

\section{Domain description}

The paper considers a natural convection flow in unstratified rectangular building with multiple- upper vents induced by stack- driven airflow. The building envelope has air as the connecting fluid and separated from one another by vertical- vents of height $\left(y^{*}\right)$ and constant width of the vents $\left(x_{w}\right)$ which is shown in Figure 1. The density, velocity, temperature and pressure of air maintained at $\rho_{a}, U^{*}, T^{*}$ and $P$. 


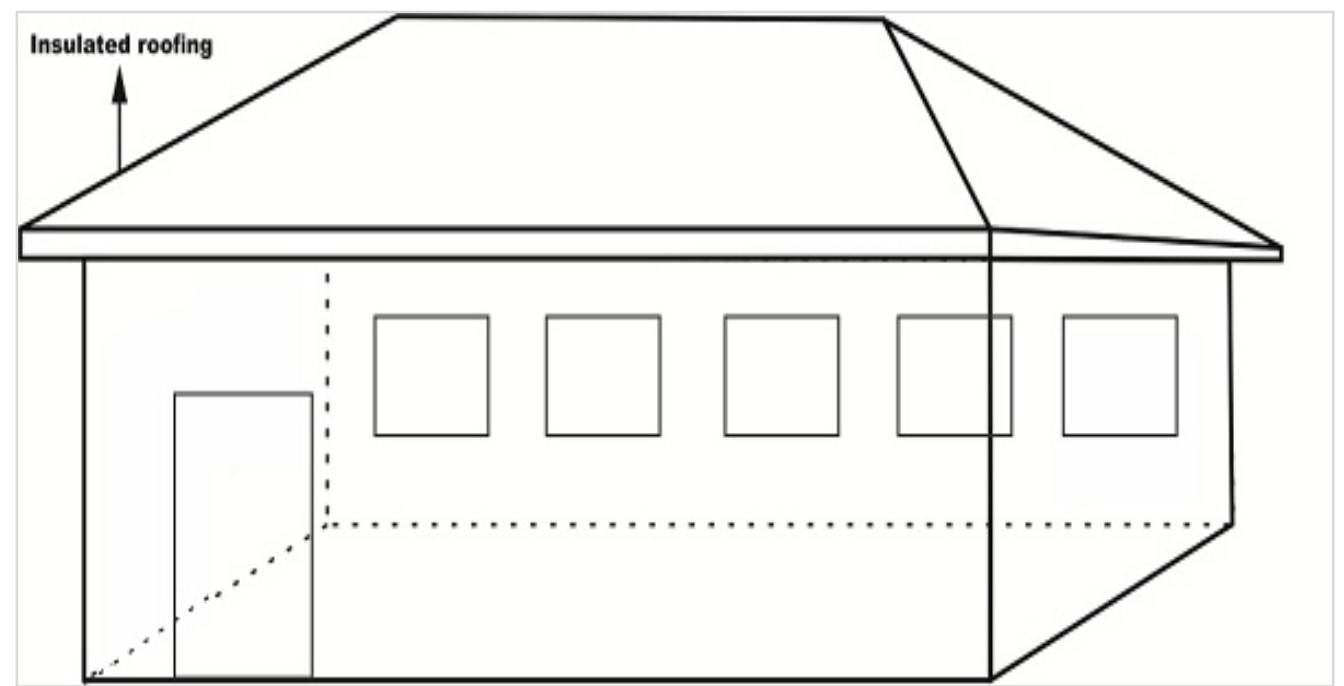

Figure 1 Diagram of the building envelope

\section{Model formulation}

The preliminary assumptions worked in the study are, flow is assumed to be depend on the height of the vents, steady flow with no internal source so as the density of air will be nearly constant like incompressible fluid ( $\rho \_a \approx$ constant) and the pressure be a component along the width of the vents in the building. The airflow induced by Stack- driven effect is shown in Figure 2.

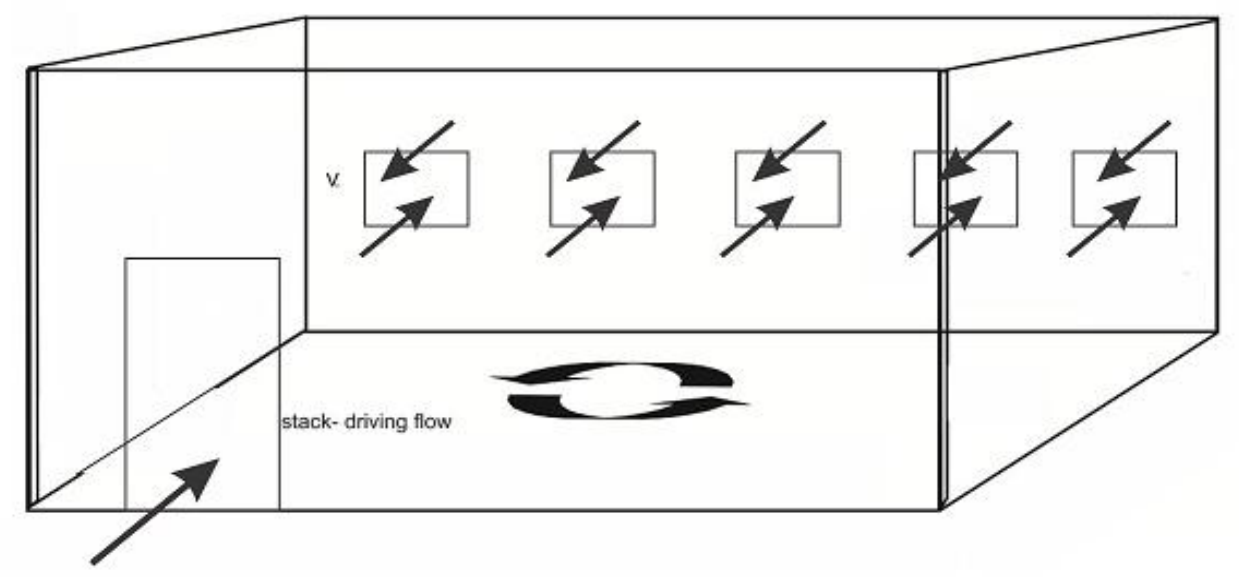

Figure 2 Schematic diagram of airflow in building induced by stack- driven effect

Under the usual assumption of reduced gravity, the governing equations in dimensional form of the momentum and energy equations are,

$$
\begin{aligned}
& \frac{\partial u}{\partial t}+v_{0} \frac{\partial u}{\partial y}=g \beta \Delta T+v \frac{\partial^{2} u}{\partial y^{2}} . \\
& \frac{\partial T}{\partial t}+v_{0} \frac{\partial u}{\partial y}=\alpha \frac{\partial^{2} T}{\partial y^{2}} .
\end{aligned}
$$

with the initial and boundary conditions that satisfy the problem,

$v_{0}=$ const. $, u=0, u(0, t)=0, T=-\theta_{0}, T(0, t)=0$ at $y=0$ and $u=0, u(1, t)=0, T=1-\theta_{0}, T(1, t)=0$ at $y=1$.
Scaling $y$ with $Y L$, velocity $u$ with $\frac{U^{*} g \beta \Delta \theta L^{2}}{\alpha}, t=\frac{t^{*} L^{2}}{\alpha}$, and introducing $T$ with $T^{*} \Delta T+T_{a}$.

The governing equations in (1), (2) and (3) are transformed into dimensionless form as,

$$
\begin{aligned}
& \frac{\partial U^{*}}{\partial t^{*}}-C \frac{\partial U^{*}}{\partial Y}=\operatorname{Pr} \frac{\partial^{2} U^{*}}{\partial Y^{2}}+\operatorname{PrGr} T^{*}\left(Y, t^{*}\right) \\
& \frac{\partial T^{*}}{\partial t^{*}}-C \frac{\partial T^{*}}{\partial Y}=\frac{\partial^{2} T^{*}}{\partial Y^{2}}
\end{aligned}
$$

with the following dimensionless boundary conditions as, 
Muhammad Auwal Lawan et al.

$U^{*}=0, U_{u}^{*}\left(0, t^{*}\right)=0, T^{*}=-\theta_{0}, T_{u}^{*}\left(0, t^{*}\right)=0$ at $Y=0$

and $U^{*}=0, U_{u}^{*}\left(1, t^{*}\right)=0, \frac{\partial U^{*}\left(1, t_{\max }\right)}{\partial Y}=U_{0}, T^{*}=1-$

$\theta_{0}, T_{u}^{*}\left(1, t^{*}\right)=0, T_{u}^{*}\left(1, t_{\max }\right)=\operatorname{sint}^{*}$ at $Y=1$.

where, $C=-v_{0} P r$.

The steady state equation for (5) is,

$\frac{d^{2} T^{*}}{d Y^{2}}+C \frac{\partial T^{*}}{\partial Y}=0$

solving equation (7) and applying boundary condition (6), we obtain steady state solution for temperature distributions as,

$T^{*}(Y)=-\theta_{0}+\frac{e^{C}}{1-e^{C}}\left(e^{-C Y}-1\right)$

The unsteady state equation for (5) is maintained as, $\frac{\partial T^{*}}{\partial t^{*}}-C \frac{\partial T^{*}}{\partial Y}=\frac{\partial^{2} \dot{T}^{*}}{\partial Y^{2}}$

steady and unsteady part of solution is,

$T^{*}\left(Y, t^{*}\right)=T^{*}(Y)+T_{u}^{*}\left(Y, t^{*}\right)$

The separation is valid for unsteady part solution as, $\frac{\partial T_{u}^{*}}{\partial t^{*}}-C \frac{\partial T_{u}^{*}}{\partial Y}=\frac{\partial^{2} T_{u}^{*}}{\partial Y^{2}}$

solving equation (10) and applying boundary condition (6), we obtain the unsteady state solution for temperature distributions as,

$T_{u}^{*}\left(Y, t^{*}\right)=e^{-\left(P_{1}^{2} t+\frac{C}{2}\right)}\left(C_{1} \cosh d Y+C_{2} \sinh d Y\right)$

which can be further simplify and obtains,

$T_{u}^{*}\left(Y, t^{*}\right)=\frac{\sin t^{*}}{\cosh d} e^{\left(P_{1}^{2}\left(t_{\max }-t^{*}\right)+\frac{c}{2}\right)} \cosh d Y$

where, $C_{1}=0, C_{2}=\frac{\sin t^{*}}{\cosh d} e^{\left(P_{1}^{2} t_{\max }+\frac{C}{2}\right)}$ for,$d=\frac{\sqrt{C^{2}-4 P_{1}^{2}}}{2}$,

$0<P_{1} \leq \frac{C}{2}$ at $t^{*} \geq 0$.

Therefore, the temperature distributions across the vents is,

$T^{*}\left(Y, t^{*}\right)=$

$-\theta_{0}+\frac{e^{C}}{1-e^{C}}\left(e^{-C Y}-1\right)+\frac{\sin t^{*}}{\operatorname{coshd}} e^{\left(P_{1}^{2} t_{\max }-t^{*}\right)} \cosh d Y$

The unsteady state equation for (4) is maintained as,

$\frac{\partial U^{*}}{\partial t^{*}}-C \frac{\partial U^{*}}{\partial Y}=\operatorname{Pr} \frac{\partial^{2} U^{*}}{\partial Y^{2}}+\operatorname{PrGr} T^{*}\left(Y, t^{*}\right)$

$\frac{\partial U^{*}}{\partial t^{*}}-C \frac{\partial U^{*}}{\partial Y}=\operatorname{Pr} \frac{\partial^{2} U^{*}}{\partial Y^{2}}+\operatorname{Pr} \operatorname{Gr}\left(-\theta_{0}+\frac{e^{C}}{1-e^{c}}\left(e^{-C Y}-1\right)+\right.$

$\left.\frac{\sin t^{*}}{\cosh d} e^{\left(P_{1}^{2} t_{\max }-t^{*}\right)} \cosh d Y\right)$

The steady state equation of (14) is,

$\operatorname{Pr} \frac{\partial^{2} U^{*}}{\partial Y^{2}}+C \frac{\partial U^{*}}{\partial Y}=\operatorname{Pr} G r\left(-\theta_{0}+\frac{e^{C}}{1-e^{C}}\left(e^{-C Y}-1\right)\right)$

solving equation (15) and applying boundary condition (6), we obtain the steady state solution for velocity distributions as,

$U^{*}(Y)=C_{3}+C_{4} e^{v_{0} Y}+\frac{G r}{C^{2}\left(1-e^{-C}\right)}\left[\left(\theta_{0}\left(1-e^{-C}\right)-\right.\right.$

1) $\left.C Y-e^{-C Y}\left(1+\frac{P r}{1-P r}\right)+\operatorname{Pr}\left(1-\theta_{0}\left(1-e^{-C}\right)\right)\right]$

which can be further simplify and obtains,

$$
\begin{aligned}
& U^{*}(Y)=\frac{G r}{C^{2}\left(1-e^{-C}\right)\left(1-e^{v_{0}}\right)}\left[( 1 + \frac { P r } { 1 - P r } ) \left(e^{-C}-e^{v_{0}}-\right.\right. \\
& \left.e^{v_{0} Y}\left(e^{-C}-1\right)-e^{-C Y}\left(1-e^{v_{0}}\right)\right)+\left(1-\theta_{0}(1-\right. \\
& \left.\left.e^{-C}\right)\right)\left(C-\operatorname{Pr}\left(1-e^{v_{0}}\right)-C e^{v_{0} Y}+\left(1-e^{v_{0}}\right)(P r-\right. \\
& C Y))] .
\end{aligned}
$$

where,

$C_{3}=\frac{\left(1+\frac{P r}{1-P r}\right)\left(e^{-C}-e^{v_{0}}\right)+\left(1-\theta_{0}\left(1-e^{-C}\right)\right)\left(C-P r\left(1-e^{v_{0}}\right)\right)}{C^{2}\left(1-e^{-C}\right)\left(1-e^{v_{0}}\right)}, C_{4}=$

$-G r \frac{\left[\left(1+\frac{P r}{1-P r}\right)\left(e^{-C}-1\right)+C\left(1-\theta_{0}\left(1-e^{-C}\right)\right)\right]}{C^{2}\left(1-e^{-C}\right)\left(1-e^{v_{0}}\right)}$.

equation (4) becomes,

$\frac{\partial U^{*}}{\partial t^{*}}-C \frac{\partial U^{*}}{\partial Y}=\operatorname{Pr} \frac{\partial^{2} U^{*}}{\partial Y^{2}}+\operatorname{PrGr}\left(-\theta_{0}+\frac{e^{c}}{1-e^{c}}\left(e^{-C Y}-1\right)+\right.$

$\left.\frac{\sin t^{*}}{\operatorname{coshd}} e^{\left(P_{1}^{2} t_{\max }-t^{*}\right)} \cosh d Y\right)$.

solving equation (18) and applying boundary condition (6), we obtain the unsteady state solution for velocity distributions as,

$U_{u}^{*}\left(Y, t^{*}\right)=$

$\frac{\left.U_{0} \sin K Y e^{P_{2}^{2}\left(\left(t_{\max }-t^{*}\right)-\frac{1}{2} v_{0}(1-Y)\right.}\right)}{K \cosh K-\frac{C}{2 P r} \sin K}-\frac{\sin t^{*} e^{P_{1}^{2}\left(t_{\max }-t^{*}\right)}}{2 \cosh d}\left(\frac{e^{d Y}}{1+P_{1}^{2}+d C}+\right.$

$\left.\frac{e^{d Y}}{1+P_{1}^{2}-d C}\right)-\theta_{0} t^{*}+C \theta_{0} Y+\frac{\operatorname{Pr} Y^{2} \theta_{0}}{2}+\frac{e^{C}}{1-e^{C}}\left(t^{*}-C Y-\right.$

$\left.\frac{\operatorname{Pr} Y^{2}}{2}\right)$

where, $C_{5}=0, C_{6}=\frac{U_{0} e^{\left(P_{2}^{2} t_{\max }-\frac{1}{2} v_{0}\right)}}{K \cosh K-\frac{C}{2 P r} \sin K}, K=\frac{\sqrt{C^{2}-4 P r P_{2}^{2}}}{2 P r}$

Therefore, the velocity distributions across the vents is,

$$
\begin{aligned}
& U^{*}\left(Y, t^{*}\right)=\frac{G r}{C^{2}\left(1-e^{-C}\right)\left(1-e^{v_{0}}\right)}\left[( 1 + \frac { P r } { 1 - P r } ) \left(e^{-C}-e^{v_{0}}-\right.\right. \\
& \left.e^{v_{0} Y}\left(e^{-C}-1\right)-e^{-C Y}\left(1-e^{v_{0}}\right)\right)+\left(1-\theta_{0}(1-\right. \\
& \left.\left.e^{-C}\right)\right)\left(C-\operatorname{Pr}\left(1-e^{v_{0}}\right)-C e^{v_{0} Y}+\left(1-e^{v_{0}}\right)(P r-\right. \\
& C Y))]+\frac{\left.U_{0} \sin K Y e^{P_{2}^{2}\left(\left(t_{\max }-t^{*}\right)-\frac{1}{2} v_{0}(1-Y)\right.}\right)}{K \cosh K-\frac{C}{2 P r} \sin K}- \\
& \frac{\operatorname{sint}^{*} e^{P_{1}^{2}\left(t_{\max }-t^{*}\right)}}{2 \cosh d}\left(\frac{e^{d Y}}{1+P_{1}^{2}+d C}+\frac{e^{-d Y}}{1+P_{1}^{2}-d C}\right)-\theta_{0} t^{*}+C \theta_{0} Y+ \\
& \frac{P r Y^{2} \theta_{0}}{2}+\frac{e^{C}}{1-e^{C}}\left(t^{*}-C Y-\frac{P r Y^{2}}{2}\right)
\end{aligned}
$$

after integrating (20) one will obtain volumetric airflow as,

$$
\begin{aligned}
& Q^{*}\left(Y, t^{*}\right)=A_{T} c_{d}\left[\frac { G r } { C ^ { 2 } ( 1 - e ^ { - C } ) ( 1 - e ^ { v _ { 0 } ) } } \left(\left(1+\frac{P r}{1-P r}\right)\left(\left(e^{-C}-e^{v_{0}}\right) \frac{Y}{2}\right)-\right.\right. \\
& \left.\left(e^{-C}-1\right) \frac{e^{v_{0} \frac{Y}{2}}}{v_{0}}+\left(1-e^{v_{0}}\right) \frac{e^{C \frac{Y}{2}}}{C}+\frac{\left(e^{-C}-1\right)}{v_{0}}-\frac{\left(1-e^{v_{0}}\right)}{C}\right)+ \\
& \left(1-\theta_{0}\left(1-e^{-C}\right)\right)\left(-\operatorname{Pr}\left(v_{0}+\left(1-e^{v_{0}}\right)\right) \frac{Y}{2}+\operatorname{Pr}^{v_{0} \frac{Y}{2}}+\right. \\
& \left.\left(1-e^{v_{0}}\right)\left(\operatorname{Pr} \frac{Y}{2}-C \frac{Y^{2}}{8}\right)-P r\right) t^{*}+
\end{aligned}
$$

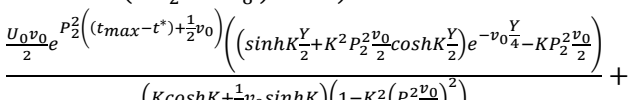




$$
\begin{aligned}
& \frac{\left(\frac{\cos t^{*}}{P_{1}^{2}}-\sin t^{*}\right) e^{P_{1}^{2}\left(t_{\max }-t^{*}\right)}}{2 b \cosh d P_{1}^{2}\left(1-\frac{1}{\left(P_{1}^{2}\right)^{2}}\right)}\left(\frac{1-e^{d \frac{Y}{2}}}{1+P_{1}^{2}+d C}+\frac{e^{-d \frac{Y}{2}}-1}{1+P_{1}^{2}-d C}\right)-\theta_{0} t^{* 2} \frac{Y}{4}+ \\
& \left(C \theta_{0} \frac{Y^{2}}{8}+\operatorname{Pr} \theta_{0} \frac{Y^{3}}{48}\right) t^{*}+\frac{e^{C}}{1-e^{C}}\left(t^{* 2} \frac{Y}{4}-C \frac{Y^{2}}{8} t^{*}-\operatorname{Pr} \frac{Y^{3}}{48} t^{*}\right)
\end{aligned}
$$

By using an idea from elementary physics for $\rho_{a}=\frac{m^{*}\left(Y, t^{*}\right)}{Q^{*}\left(Y, t^{*}\right)}$

Therefore, the mass- transfer is,

$$
\begin{aligned}
& m^{*}\left(Y, t^{*}\right)=A_{T} \rho_{a} c_{d}\left[\frac { G r } { C ^ { 2 } ( 1 - e ^ { - C } ) ( 1 - e ^ { v _ { 0 } ) } } \left(( 1 + \frac { P r } { 1 - P r } ) \left(\left(e^{-C}-\right.\right.\right.\right. \\
& \left.\left.\left.e^{v_{0}}\right) \frac{Y}{2}\right)-\left(e^{-C}-1\right) \frac{e^{v_{0} \frac{Y}{2}}}{v_{0}}+\left(1-e^{v_{0}}\right) \frac{e^{c \frac{Y}{2}}}{C}+\frac{\left(e^{-C}-1\right)}{v_{0}}-\frac{\left(1-e^{v_{0}}\right)}{C}\right)+ \\
& \left(1-\theta_{0}\left(1-e^{-C}\right)\right)\left(-\operatorname{Pr}\left(v_{0}+\left(1-e^{v_{0}}\right)\right) \frac{Y}{2}+\operatorname{Pr} e^{v_{0} \frac{Y}{2}}+\right. \\
& \left.\left(1-e^{v_{0}}\right)\left(\operatorname{Pr} \frac{Y}{2}-C \frac{Y^{2}}{8}\right)-P r\right) t^{*}+ \\
& \frac{\frac{U_{0} v_{0}}{2} e^{P_{2}^{2}\left(\left(t_{\max }-t^{*}\right)+\frac{1}{2} v_{0}\right)}\left(\left(\sinh K \frac{Y}{2}+K^{2} P_{2}^{2} \frac{v_{0}}{2} \cosh K \frac{Y}{2}\right) e^{-v_{0} \frac{Y}{4}}-K P_{2}^{2} \frac{v_{0}}{2}\right)}{\left(K \cosh K+\frac{1}{2} v_{0} \sinh K\right)\left(1-K^{2}\left(P_{2}^{2} \frac{v_{0}}{2}\right)^{2}\right)}+
\end{aligned}
$$

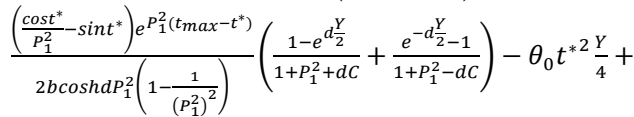

$$
\begin{aligned}
& \left.\left(C \theta_{0} \frac{Y^{2}}{8}+\operatorname{Pr} \theta_{0} \frac{Y^{3}}{48}\right) t^{*}+\frac{e^{C}}{1-e^{C}}\left(t^{* 2} \frac{Y}{4}-C \frac{Y^{2}}{8} t^{*}-\operatorname{Pr} \frac{Y^{3}}{48} t^{*}\right)\right] \text { (23) }
\end{aligned}
$$

\section{Notations and greek's words}

$C_{1}, C_{2}, C_{3}, C_{4}, C_{5}, C_{6}$ Coefficients

$P_{1}, P_{2} \quad$ Separation constants

$K, d, C$ Constants

$A_{T} \quad$ Total area of the openings in nondimensional form

$L \quad$ Line scale

$v_{0} \quad$ Constant indirect velocity of the air

$P \quad$ Air pressure in dimensional form

$x_{w} \quad$ Constant width of the vents

$y \quad$ Height of the vents in dimensional form

$Y \quad$ Height of the vents in non- dimensional form

$t \quad$ Time in dimensional form

$t^{*} \quad$ Time in non- dimensional form

$c_{d} \quad$ discharge coefficient

$U_{0} \quad$ Constant velocity of air at $y=1, t=t_{\max }$

$u \quad$ Velocity of air in dimensional form

$U^{*} \quad$ Velocity profile in non- dimensional form

$U_{u}^{*} \quad$ Unsteady velocity profile in non- dimensional form

\section{Greek Symbols}

$\rho_{a} \quad$ Ambient density of air

$T_{a} \quad$ Ambient temperature of air

$\theta_{0} \quad$ Effective thermal coefficient
$T \quad$ Air temperature in dimensional form

$\Delta T$ Change of air temperature in dimensional form

$T^{*} \quad$ Temperature profile in non- dimensional form

$\beta \quad$ Coefficient of thermal expansion

$\alpha \quad$ Thermal conductivity ratio

$v \quad$ Kinematic viscosity of fluid

\section{Non Dimensional Group \\ Pr Prandtl number \\ Gr Grashof number}

\section{Subscript}

$w \quad$ width of the vents

\section{Asymptotic behavior of the results}

Asymptotic behavior of the results obtained from equations (13), (20), (21) and (23) are plotted. The analysis of the results is done in order to see the effect of changes of parameters such as involved in the study to the overall flow across the vents while keeping other physical parameters and operating condition fixed.

The paper investigated the transient effect of constant indirect flow velocity in rectangular building with multiple- upper vents induced by stack- driven effect. Although there are three parameters of interest in the present work, effective thermal coefficient $\left(\theta_{0}\right)$, Prandtl number $(P r)$ and Grashof number $(G r)$ with time interval between $t^{*}=0.00, \mathbf{0 . 5 1}$ and $1.02 \mathrm{In}$ this section, the value of $\theta_{0}$ used is between $0.01,0.03$ and 0.05 , since, we assumed the internal heat source is very negligible. Similarly, the value for $G r$ is selected arbitrary between $G r=10.0,20.0$ and 30.00 and the value for $P r$ is $P r=0.650,0.710$ and 0.770 which is the actual value for air.

Figure 3, 4, 5, 6, 7 and 8 reveal the influence of effective thermal coefficient $\left(\theta_{0}\right)$ and Prandtl number $(P r)$ on the airflow temperature distributions across the openings. It is clearly seen that airflow temperature increase with the increase of effective thermal coefficient $\left(\theta_{0}\right)$ and Prandtl number $(P r)$.

Figure 9, 10, 11, 12, 13, 14, 15, 16 and 17 reveal the influence of effective thermal coefficient $\left(\theta_{0}\right)$, Prandtl number $(P r)$ and Grashof number $(G r)$ (is a non- dimensional group which approximate the ratio of the buoyancy to viscous force acting on a fluid), on the airflow velocity distributions across the openings. It is clearly seen that airflow velocity increase with the increase of effective thermal coefficient $\left(\theta_{0}\right)$, Prandtl number $(\operatorname{Pr})$ and Grashof number $(G r)$. This is physictally true since growing 
Prandtl number decreases thermal diffusitivity of the air.

Figure 18, 19, 20, 21, 22, 23, 24, 25 and 26 reveal the influence of effective thermal coefficient $\left(\theta_{0}\right)$, Prandtl number $(P r)$ and Grashof number $(G r)$ on the volumetric airflow in the building. can be discovered that volumetric airflow goes significantly upward with the increase of effective thermal coefficient $\left(\theta_{0}\right)$, Prandtl number $(\mathrm{Pr})$ and Grashof number $(\mathrm{Gr})$. Figure 27, 28, 29, 30, 31, 32, 33, 34 and 35 reveal the influence of effective thermal coefficient $\left(\theta_{0}\right)$, Prandtl number $(P r)$ and Grashof number $(G r)$ on the mass- transfer. It can be discovered that masstransfer goes significantly with the increase of effective thermal coefficient $\left(\theta_{0}\right), \quad$ Prandtl number $(P r)$ and Grashof number $(G r)$.

Figure 36, 37 and 38 shows the comparison between present and the previous work by [15]. The main contributions from the present work is that, effect of changes of parameters involved in the results goes significantly upward compared with the previous work. Therefore, effective thermal coefficient $\left(\boldsymbol{\theta}_{\mathbf{0}}\right)$, Prandtl number $(\boldsymbol{P r})$ and Grashof number $(\boldsymbol{G r})$ exerts significant influence on the airflow velocity, temperature distributions together with mass- transfer and volumetric airflow in the building envelope.

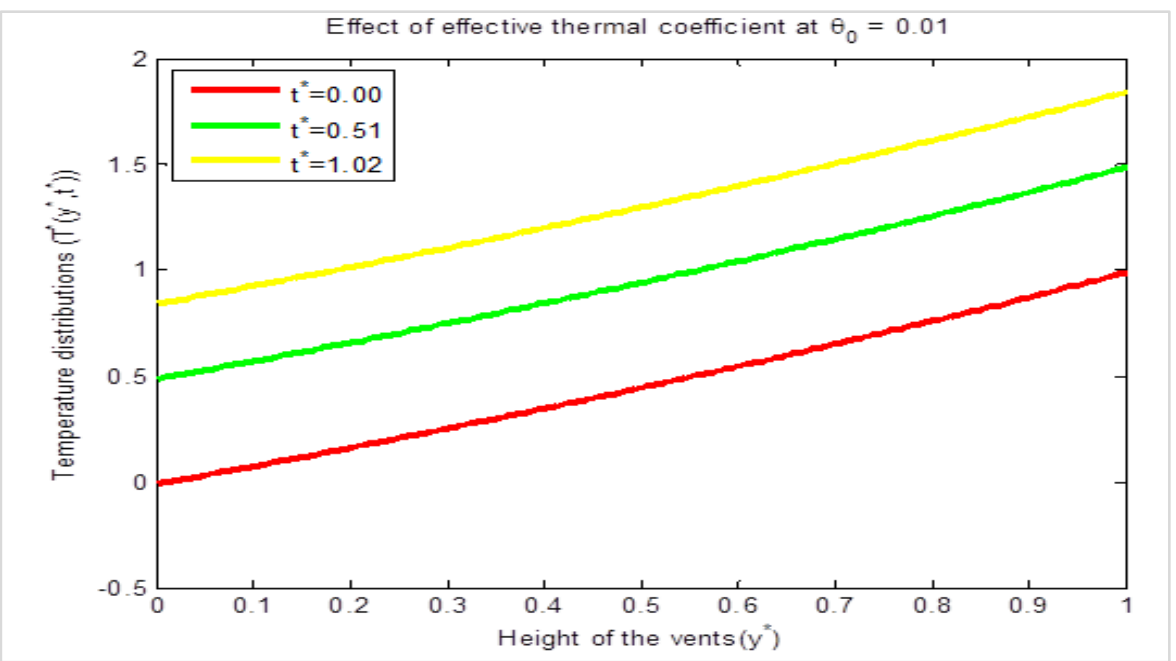

Figure 3 Airflow temperature distributions for different values of $\boldsymbol{t}^{*}\left(\boldsymbol{\theta}_{\mathbf{0}}=\mathbf{0 . 0 1}\right)$

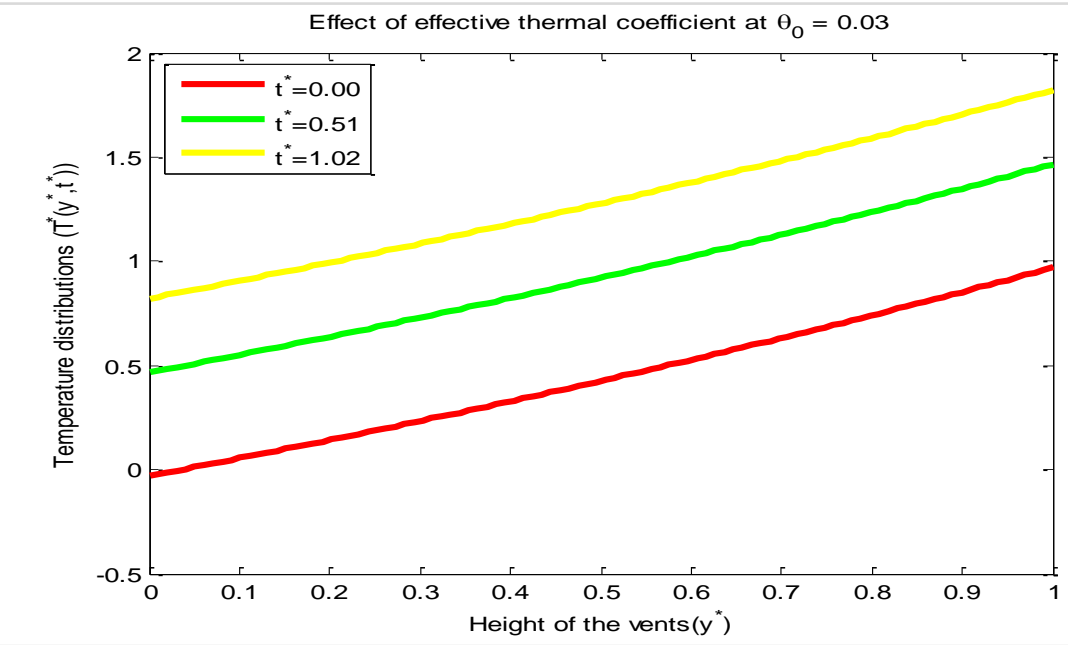

Figure 4 Airflow temperature distributions for different values of $\boldsymbol{t}^{*}\left(\boldsymbol{\theta}_{\mathbf{0}}=\mathbf{0 . 0 3}\right)$ 


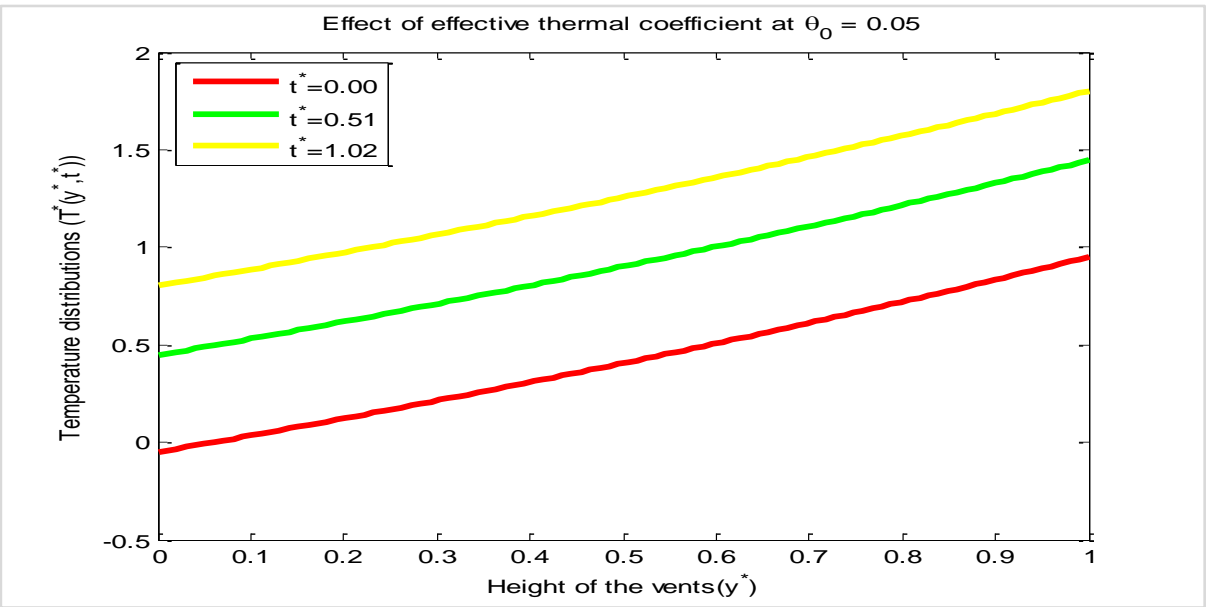

Figure 5 Airflow temperature distributions for different values of $\mathrm{t}^{\wedge *}\left(\theta \_0=0.05\right)$

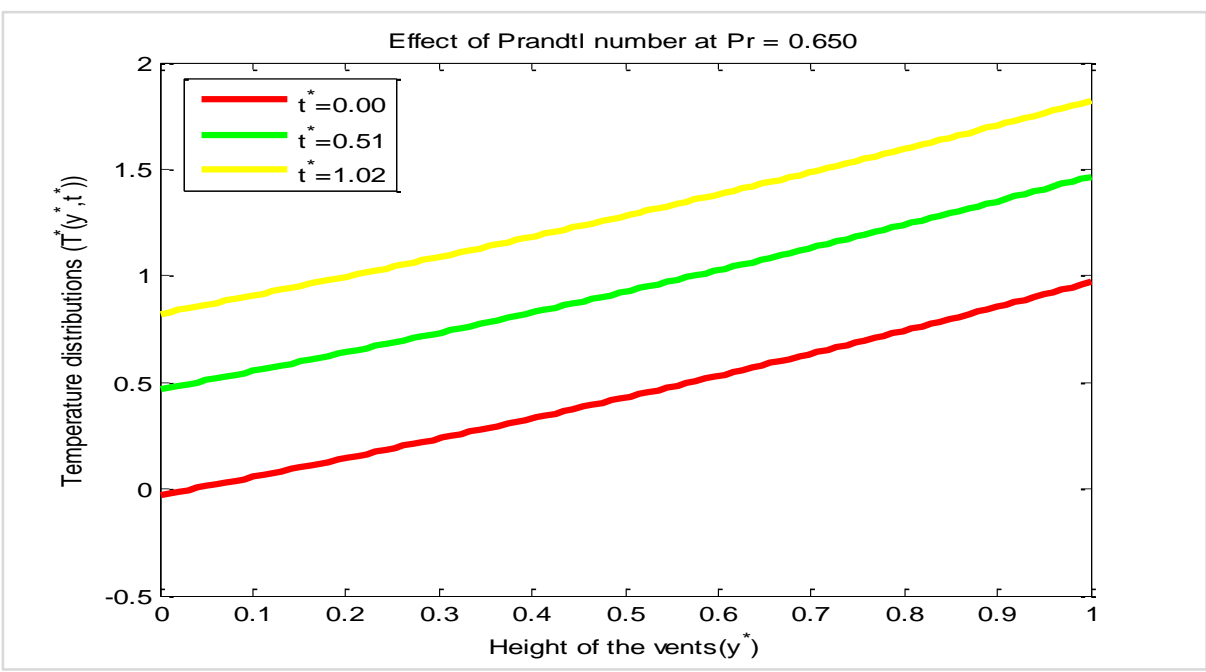

Figure 6 Airflow temperature distributions for different values of $\boldsymbol{t}^{*}\left(\operatorname{Pr}=\mathbf{0 . 6 5 0}, \boldsymbol{\theta}_{\mathbf{0}}=\mathbf{0 . 0 3}\right)$

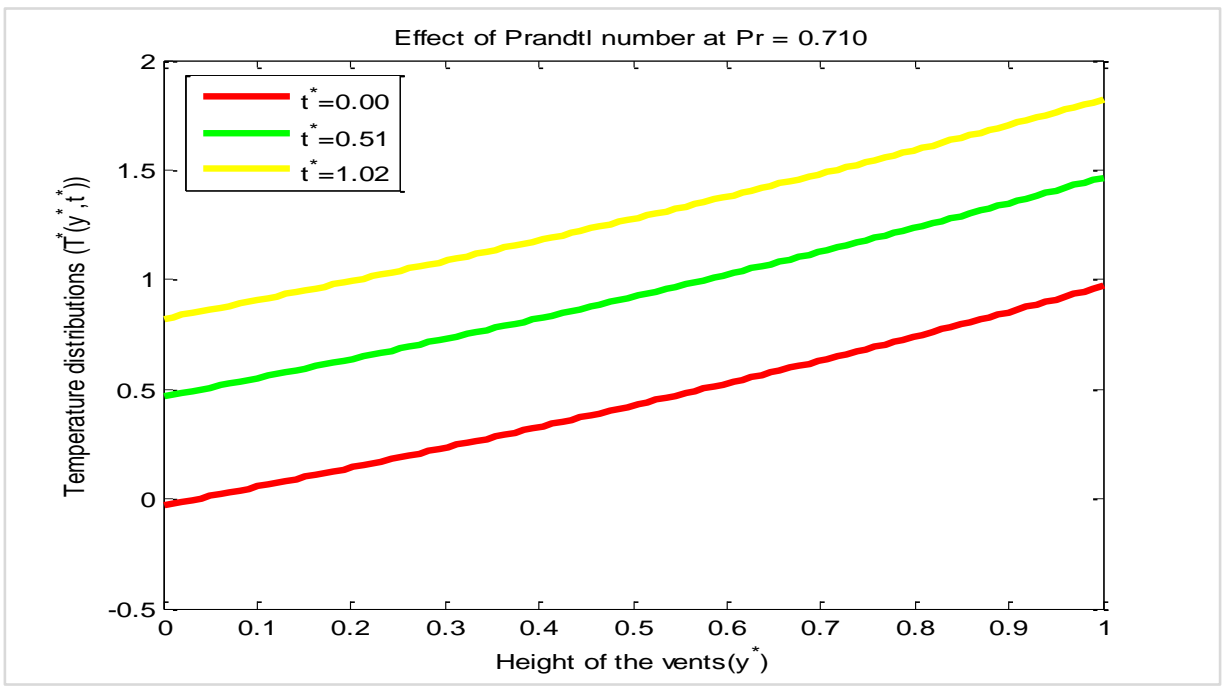

Figure 7Airflow temperature distributions for different values of $\boldsymbol{t}^{*}\left(\boldsymbol{P r}=\mathbf{0 . 7 1 0}, \boldsymbol{\theta}_{\mathbf{0}}=\mathbf{0 . 0 3}\right)$ 
Muhammad Auwal Lawan et al.

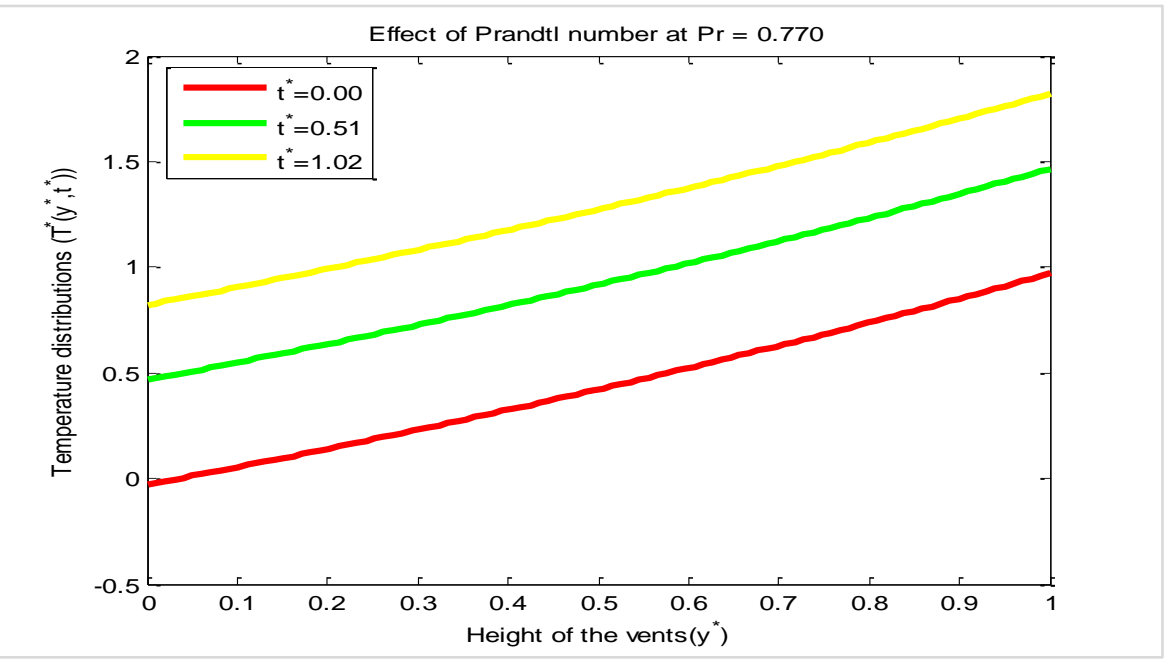

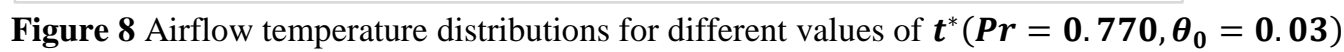

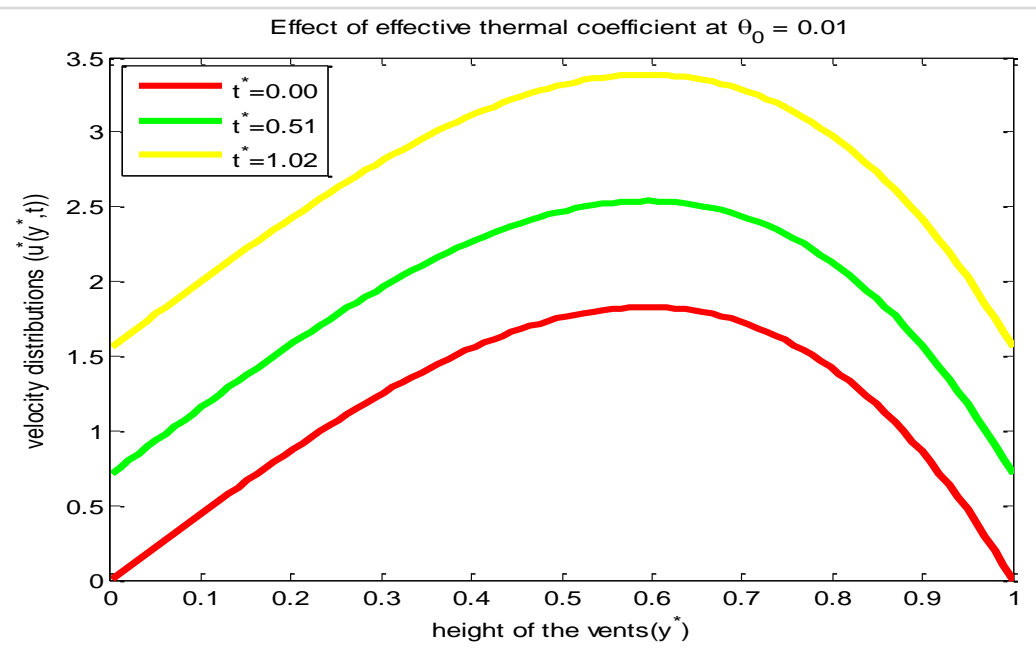

Figure 9 Airflow velocity distributions for different values of $\boldsymbol{t}^{*}\left(\boldsymbol{\theta}_{\mathbf{0}}=\mathbf{0 . 0 1}, \boldsymbol{G r}=20, \operatorname{Pr}=\mathbf{0 . 7 1 0}\right)$

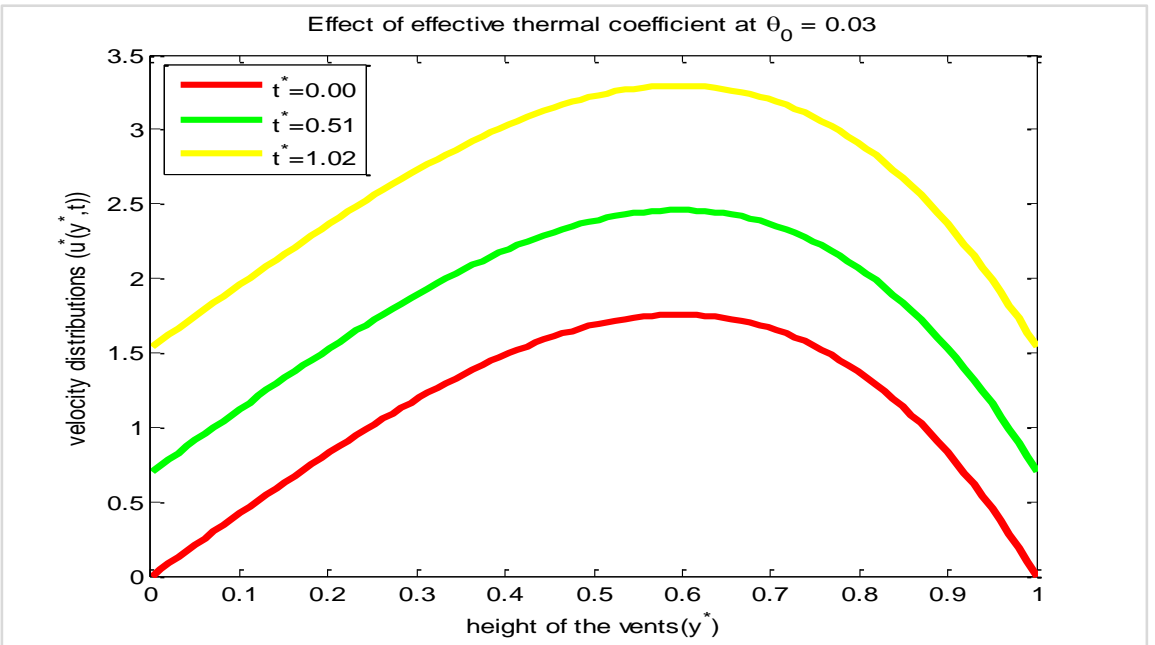

Figure 10 Airflow velocity distributions for different values of $t^{*}\left(\boldsymbol{\theta}_{\mathbf{0}}=\mathbf{0 . 0 3}, G r=20, \operatorname{Pr}=0.710\right)$ 


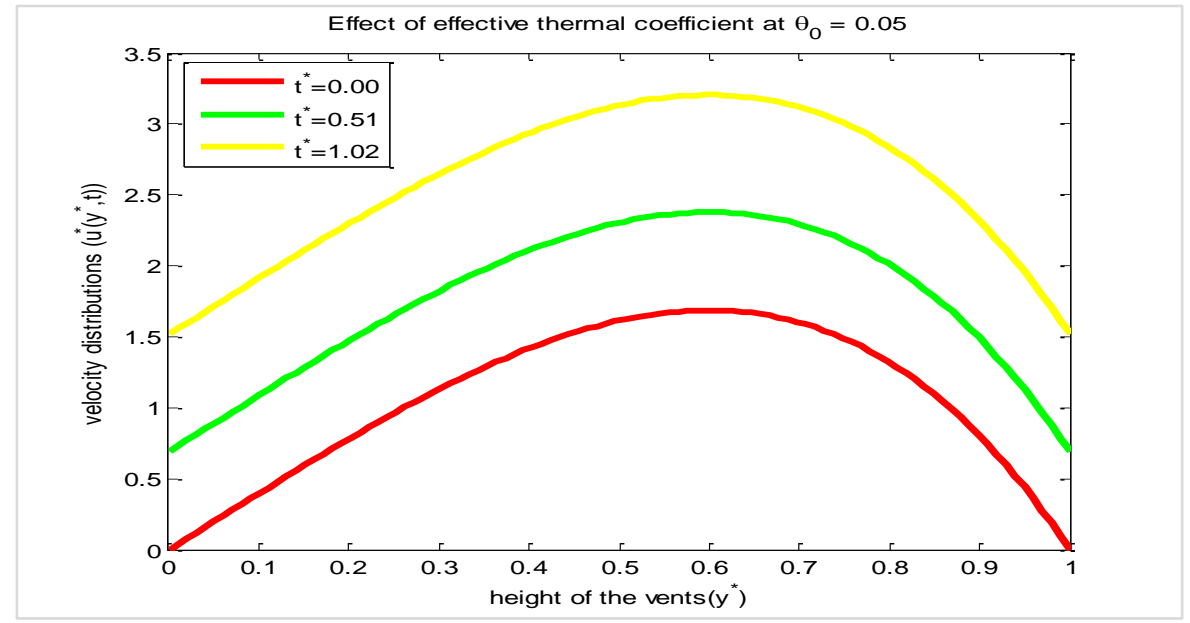

Figure 11 Airflow velocity distributions for different values of $t^{*}\left(\boldsymbol{\theta}_{\mathbf{0}}=\mathbf{0 . 0 5}, G r=20, \operatorname{Pr}=0.710\right)$

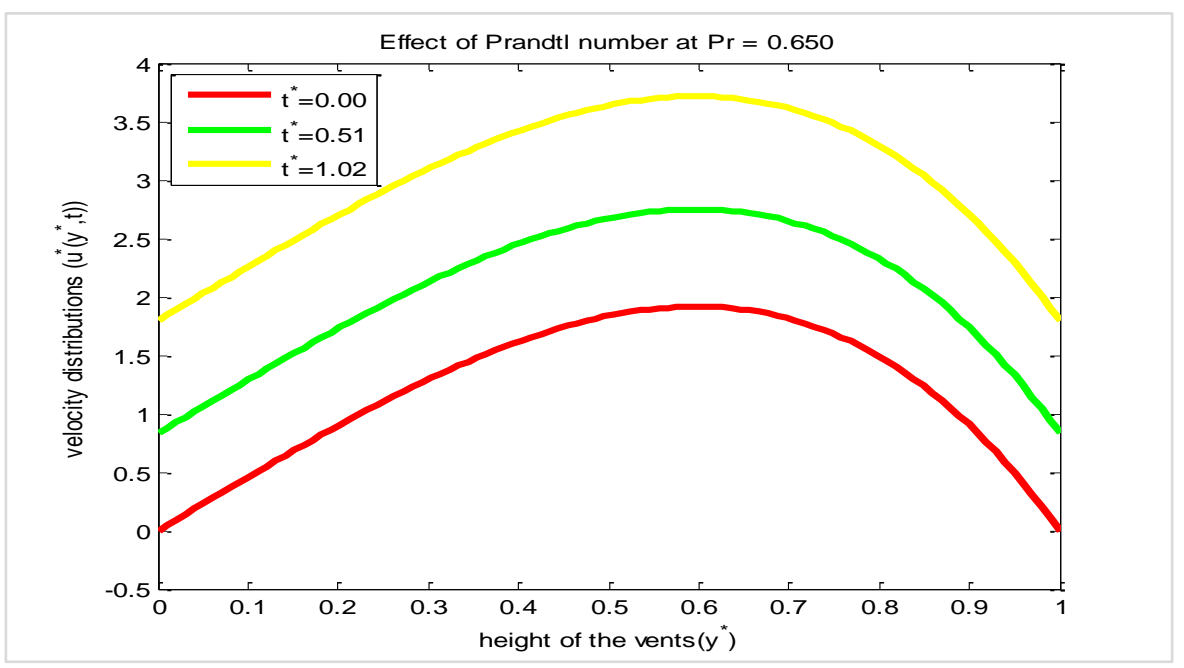

Figure 12 Airflow velocity distributions for different values of $t^{*}\left(\boldsymbol{P r}=\mathbf{0 . 6 5 0}, \theta_{0}=0.03, G r=20\right)$

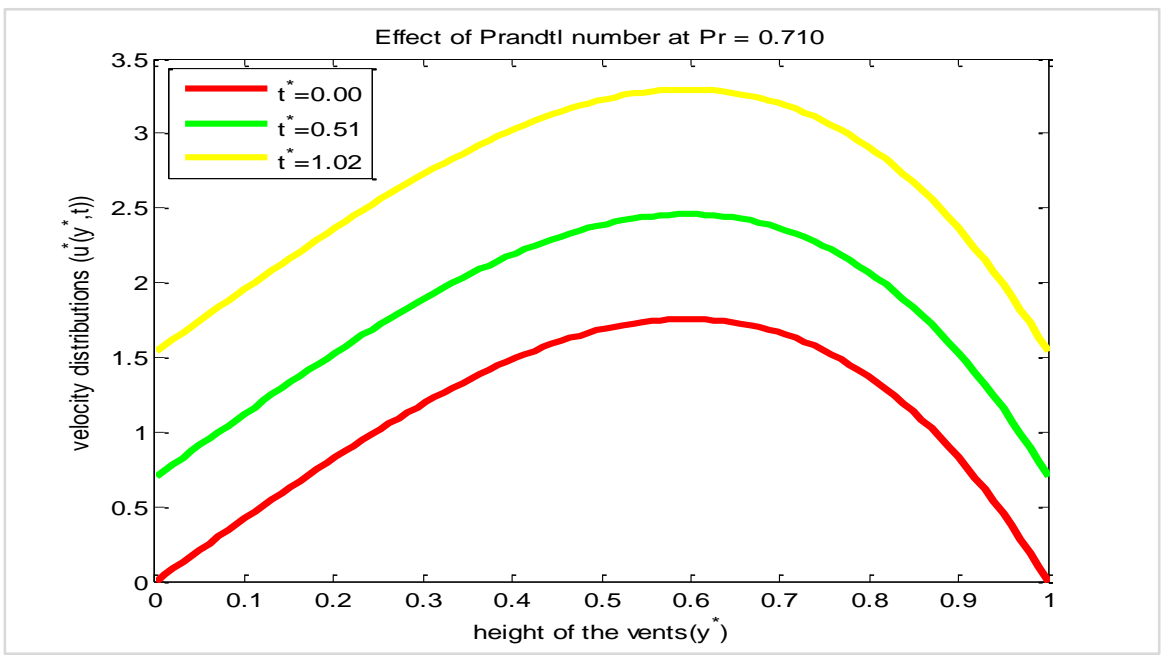

Figure 13 Airflow velocity distributions for different values of $t^{*}\left(\boldsymbol{P r}=\mathbf{0 . 7 1 0}, \theta_{0}=0.03, G r=20\right)$ 
Muhammad Auwal Lawan et al.

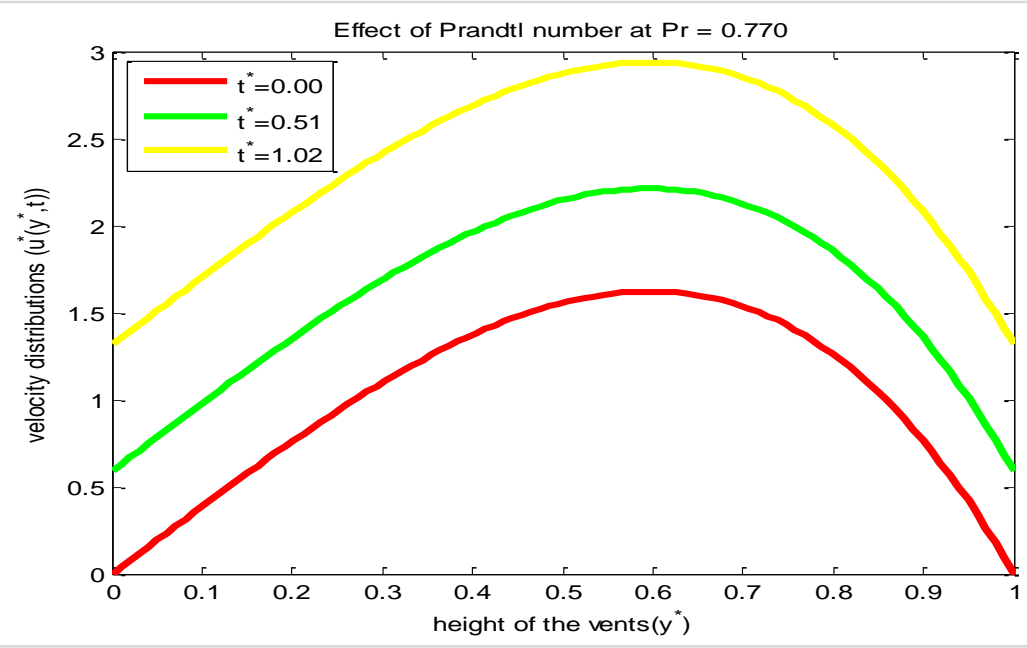

Figure 14 Airflow velocity distributions for different values of $\boldsymbol{t}^{*}\left(\operatorname{Pr}=\mathbf{0 . 7 7 0}, \boldsymbol{\theta}_{\mathbf{0}}=\mathbf{0 . 0 3}, \boldsymbol{G r}=\mathbf{2 0}\right)$

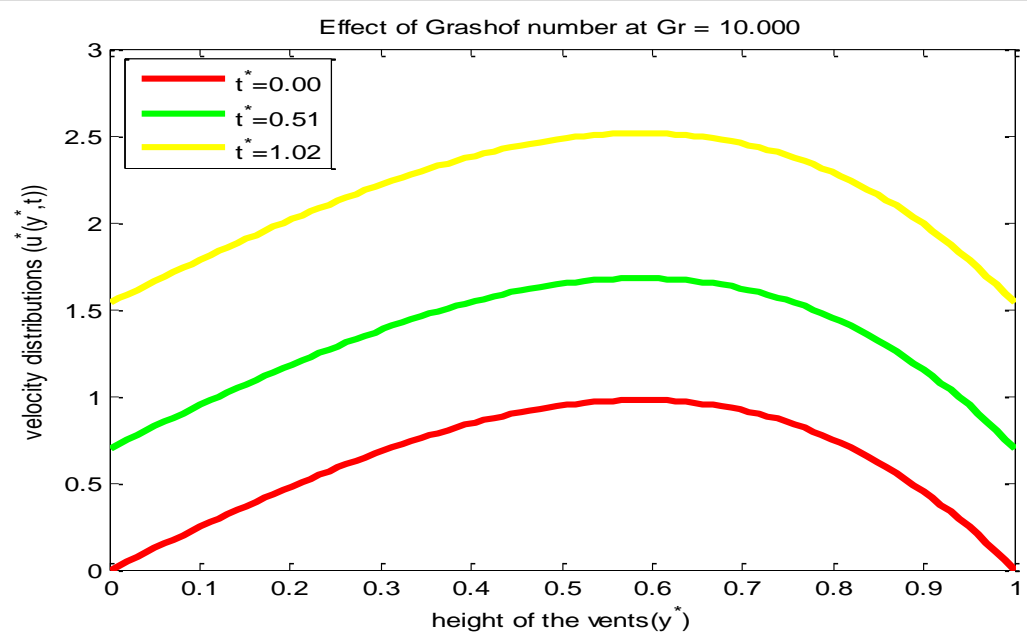

Figure 15 Airflow velocity distributions for different values of $\boldsymbol{t}^{*}\left(\boldsymbol{G r}=\mathbf{1 0}, \boldsymbol{P r}=\mathbf{0 . 7 1 0}, \boldsymbol{\theta}_{\mathbf{0}}=\mathbf{0 . 0 3}\right)$

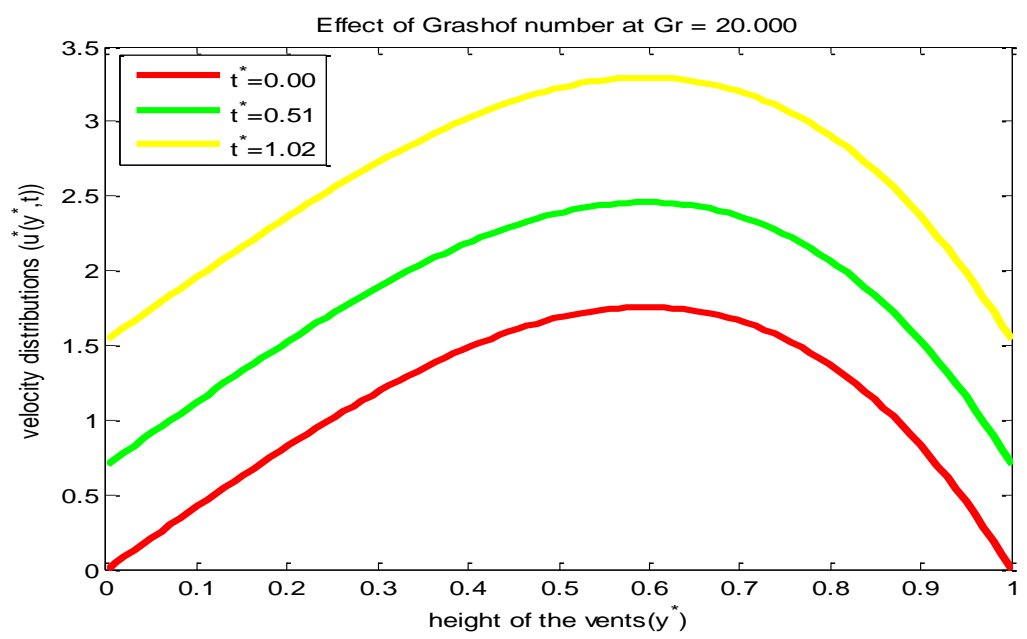

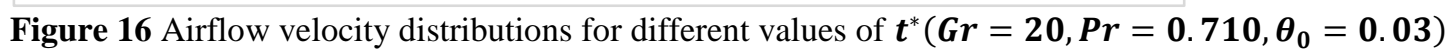
62 


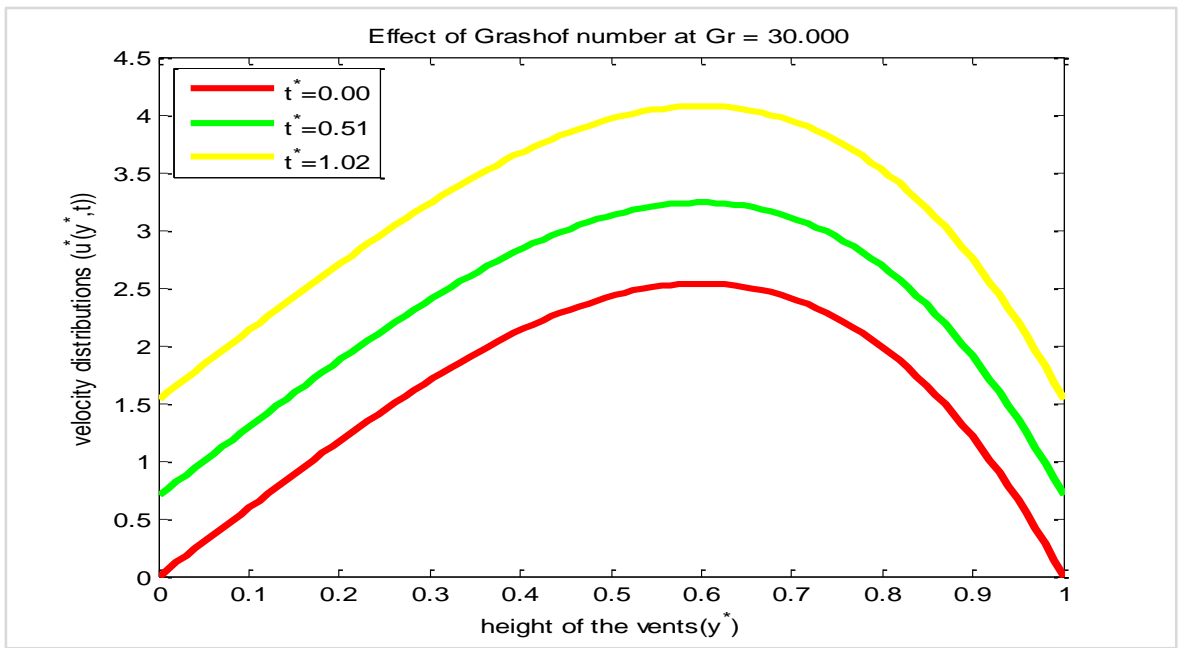

Figure 17 Airflow velocity distributions for different values of $\boldsymbol{t}^{*}\left(\boldsymbol{G r}=\mathbf{3 0}, \boldsymbol{P r}=\mathbf{0 . 7 1 0}, \boldsymbol{\theta}_{\mathbf{0}}=\mathbf{0 . 0 3}\right)$

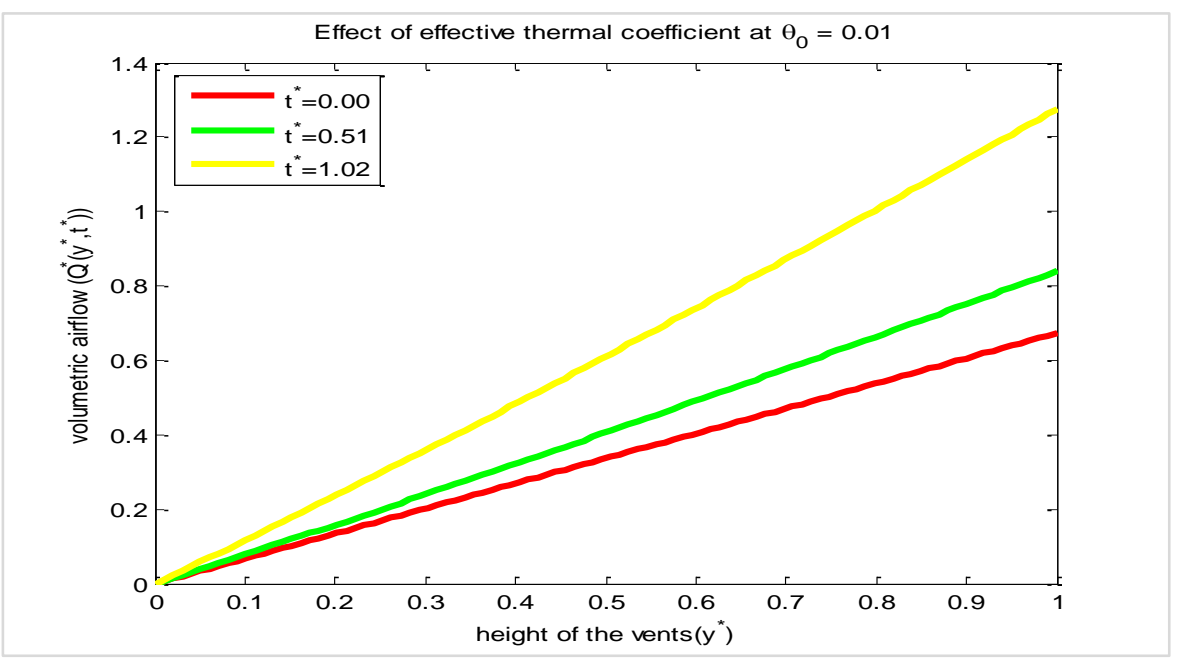

Figure 18 Volumetric airflow for different values of $\boldsymbol{t}^{*}\left(\boldsymbol{\theta}_{\mathbf{0}}=\mathbf{0 . 0 1}, \boldsymbol{G r}=20, \operatorname{Pr}=\mathbf{0 . 7 1 0}\right)$

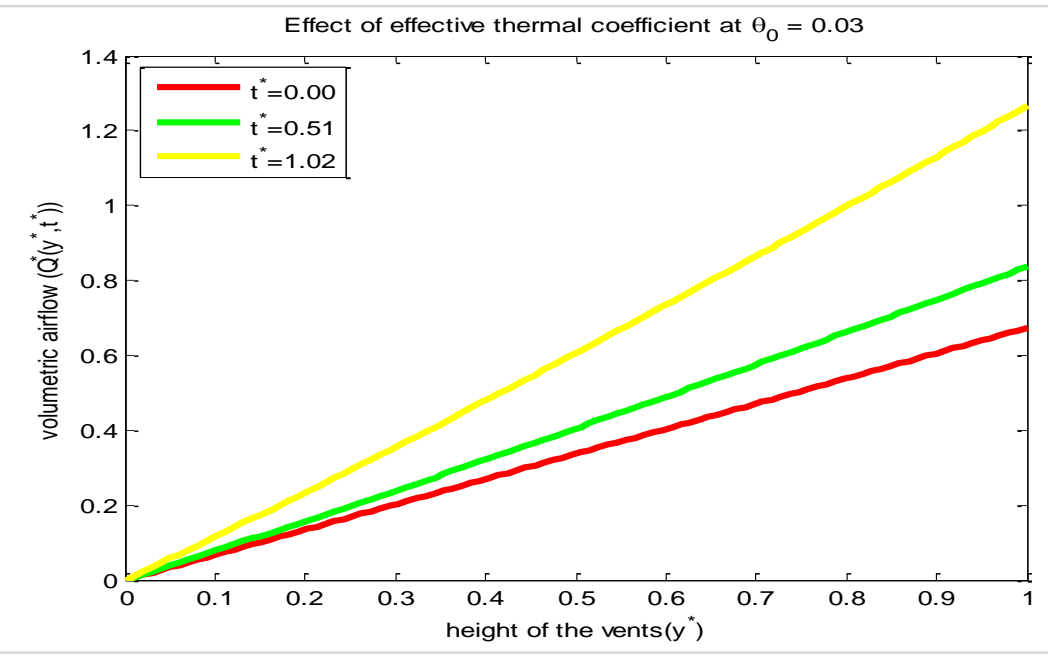

Figure 19 Volumetric airflow for different values of $\boldsymbol{t}^{*}\left(\boldsymbol{\theta}_{0}=0.03, \mathbf{G r}=\mathbf{2 0}, \operatorname{Pr}=\mathbf{0 . 7 1 0}\right)$ 
Muhammad Auwal Lawan et al.

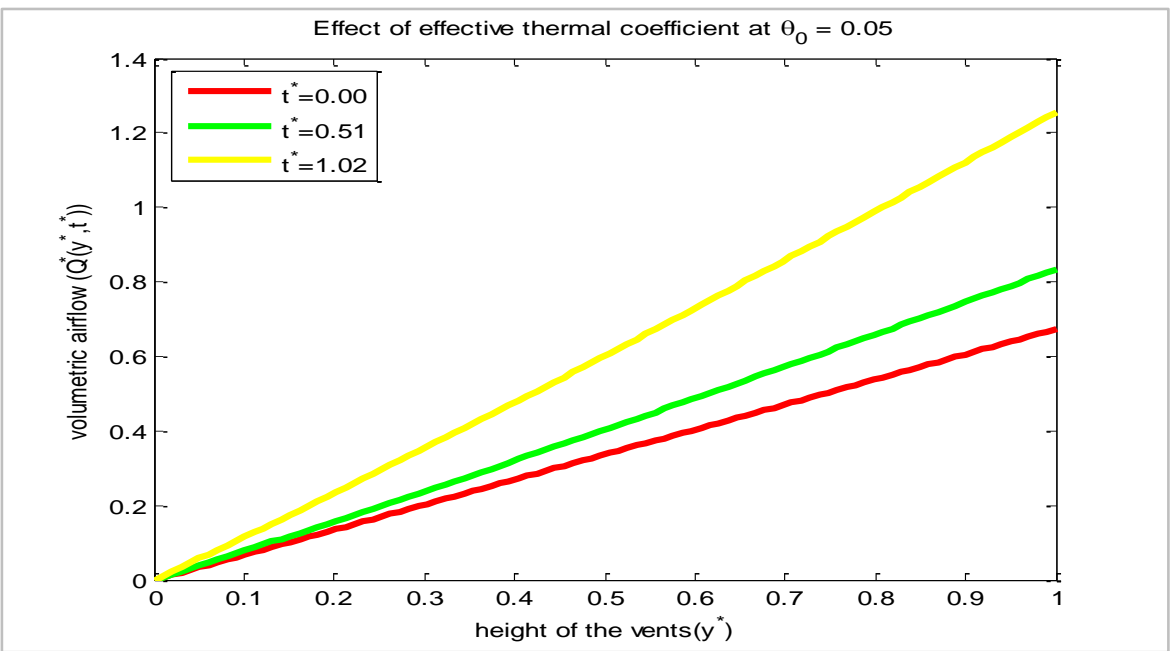

Figure 20 Volumetric airflow for different values of $t^{*}\left(\theta_{0}=0.05, G r=20, \operatorname{Pr}=0.710\right)$

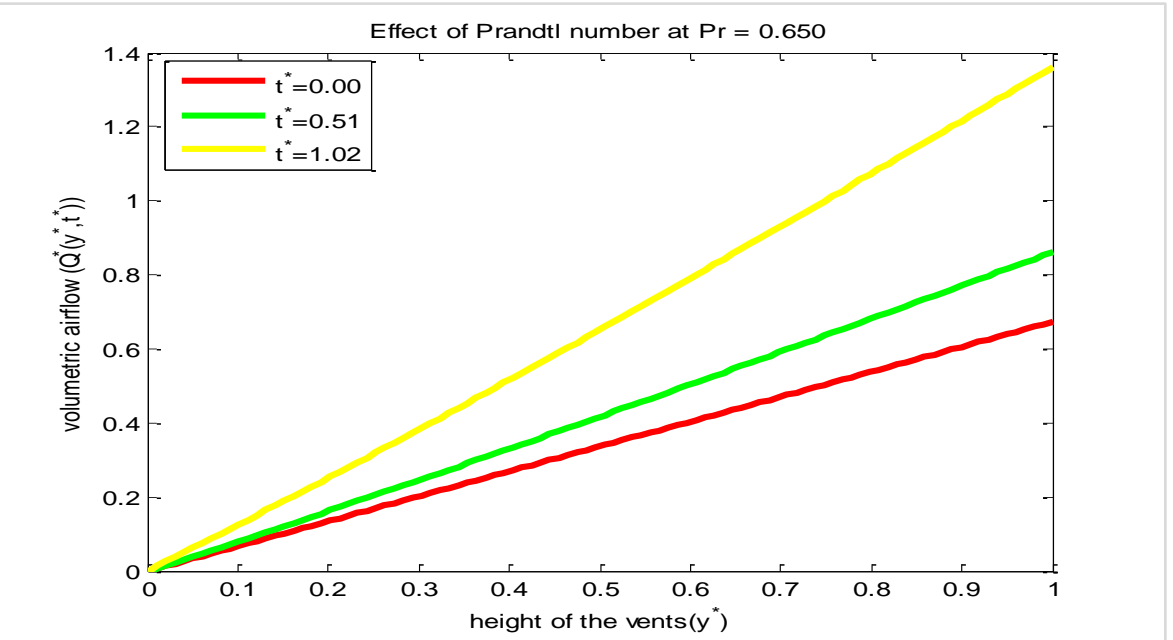

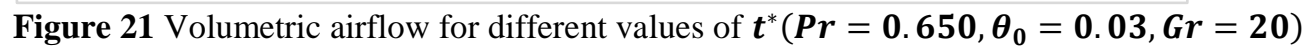

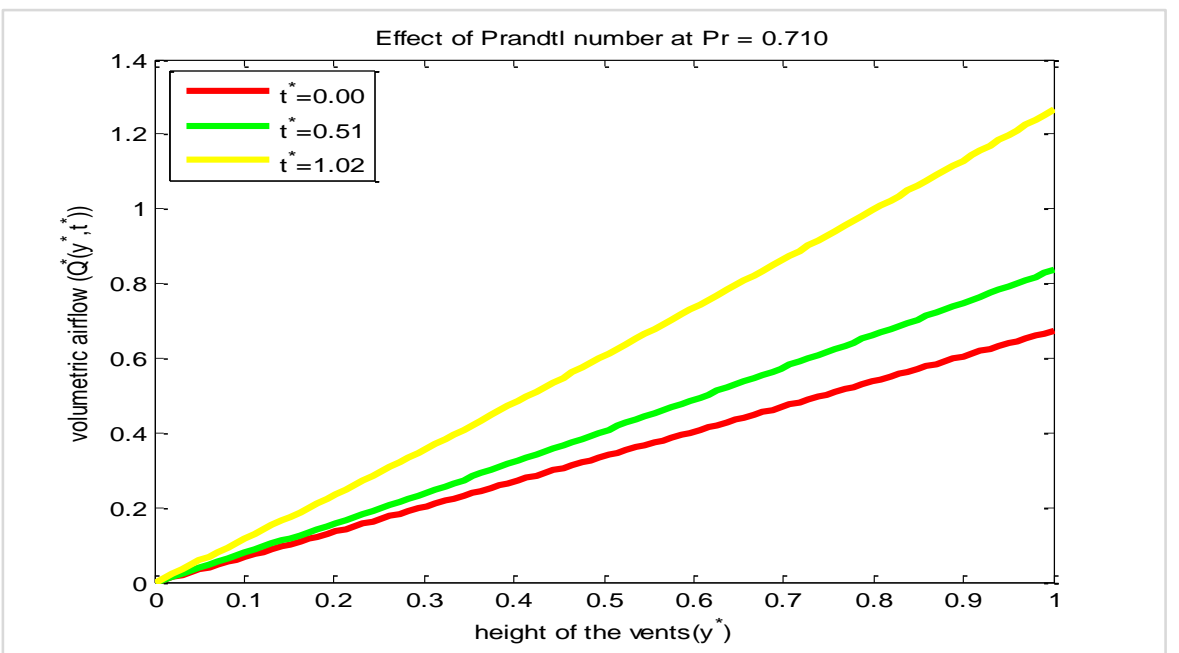

Figure 22 Volumetric airflow for different values of $t^{*}\left(\operatorname{Pr}=0.710, \theta_{0}=0.03, G r=20\right)$ 


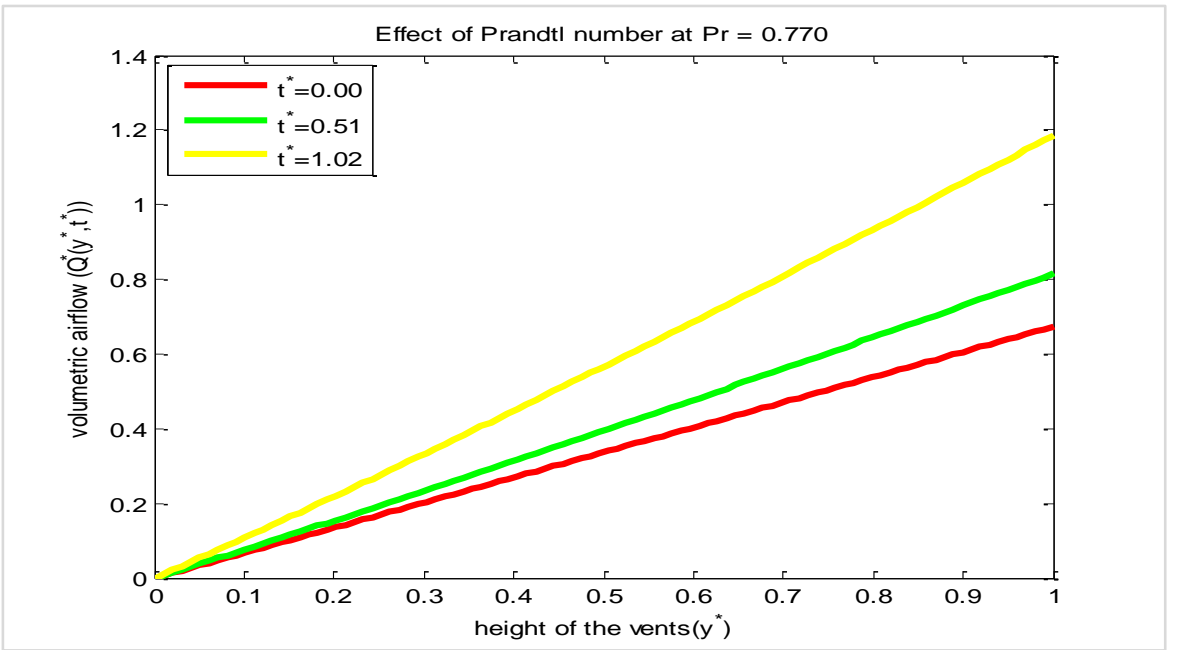

Figure 23 Volumetric airflow for different values of $\boldsymbol{t}^{*}\left(\boldsymbol{P r}=\mathbf{0 . 7 7 0}, \boldsymbol{\theta}_{\mathbf{0}}=\mathbf{0 . 0 3}, \boldsymbol{G r}=\mathbf{2 0}\right)$

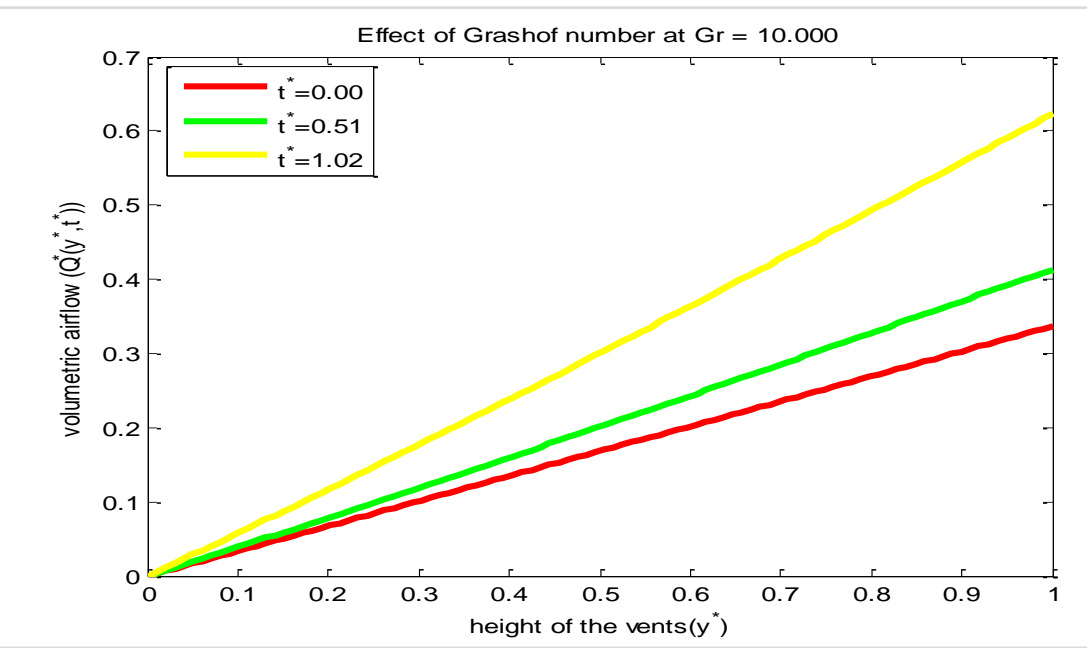

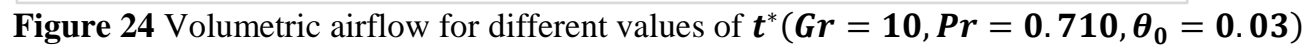

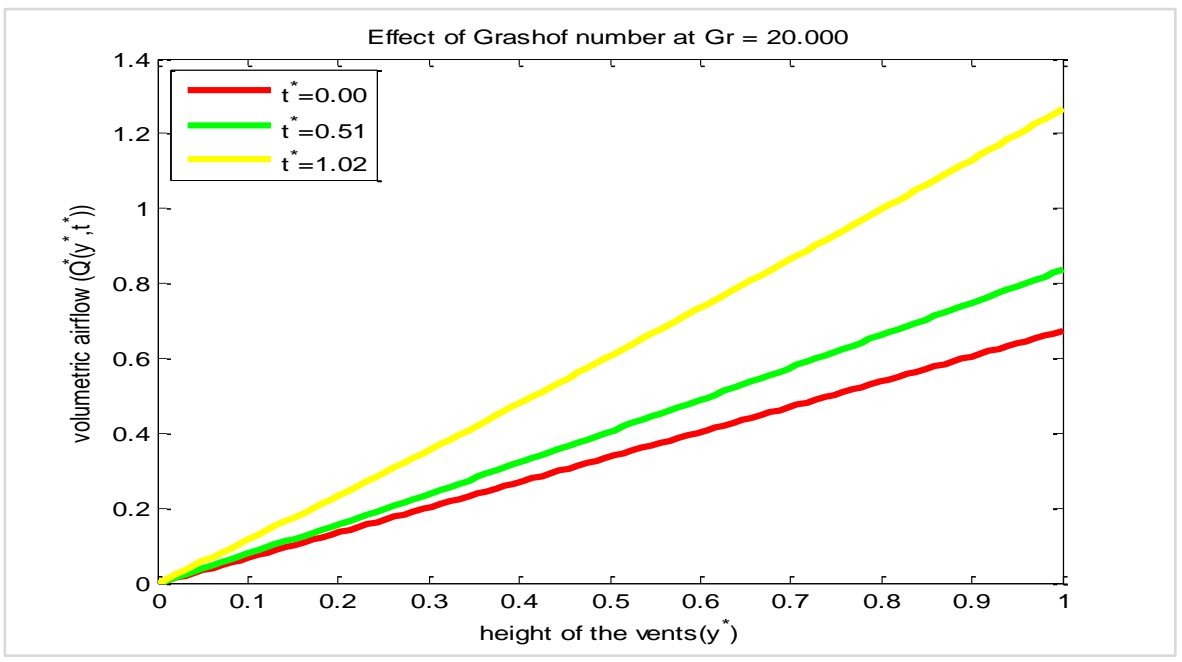

Figure 25 Volumetric airflow for different values of $\boldsymbol{t}^{*}\left(\boldsymbol{G r}=20, \boldsymbol{P r}=\mathbf{0 . 7 1 0}, \boldsymbol{\theta}_{\mathbf{0}}=\mathbf{0 . 0 3}\right)$ 
Muhammad Auwal Lawan et al.

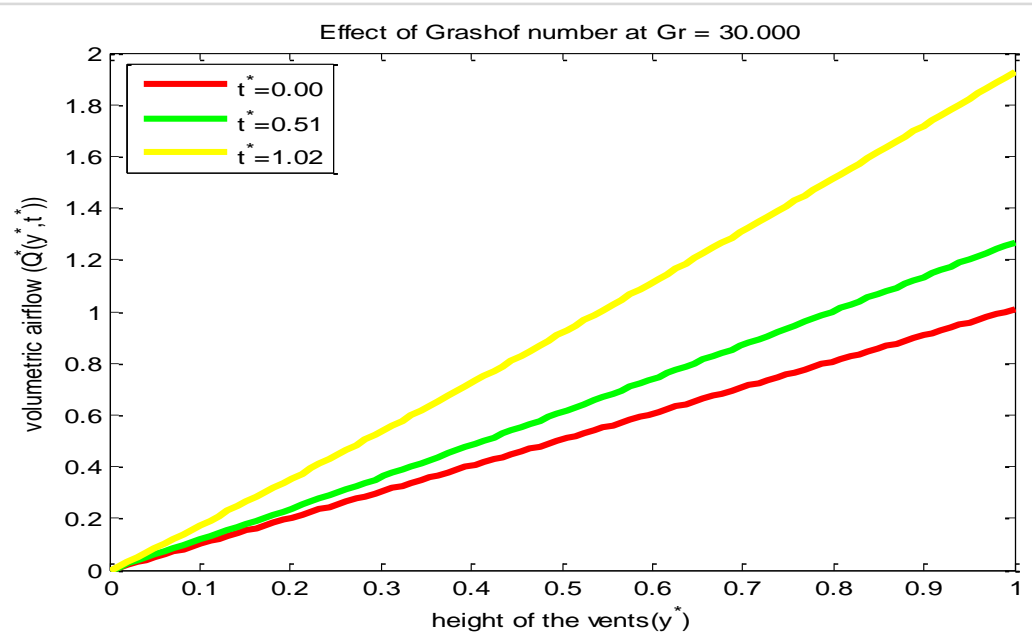

Figure 26 Volumetric airflow for different values of $t^{*}\left(G r=30, \operatorname{Pr}=0.710, \theta_{0}=0.03\right)$

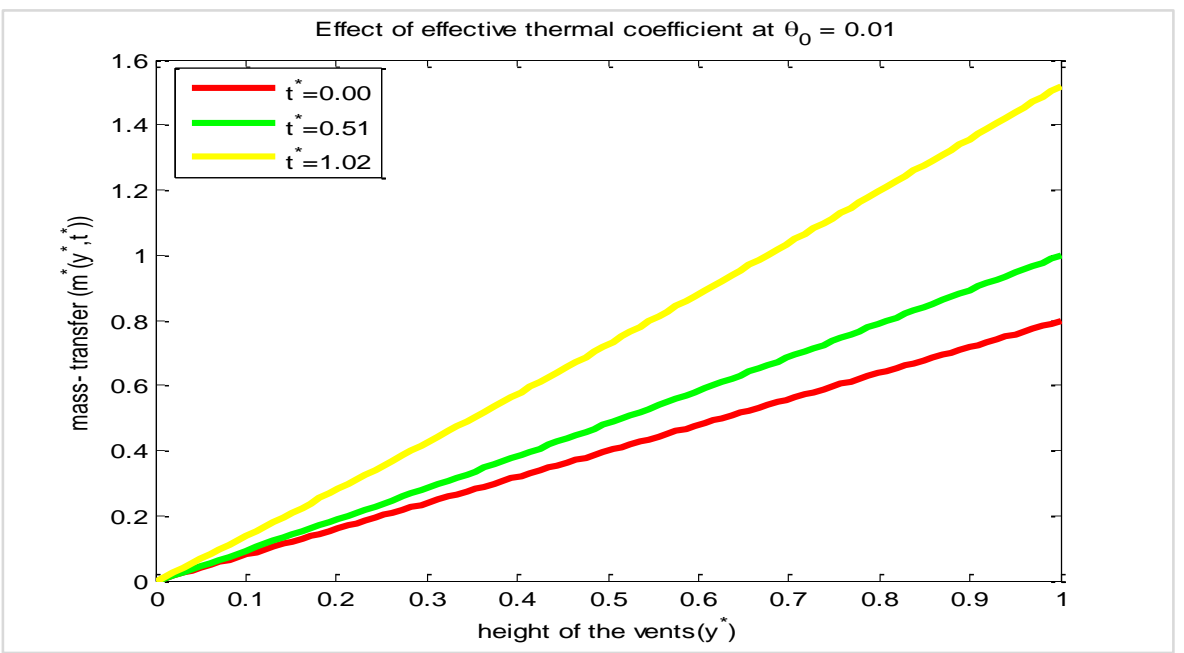

Figure 27 Mass- transfer for different values of $\boldsymbol{t}^{*}\left(\boldsymbol{\theta}_{\mathbf{0}}=\mathbf{0 . 0 1}, \boldsymbol{G r}=20, \boldsymbol{P r}=\mathbf{0 . 7 1 0}\right)$

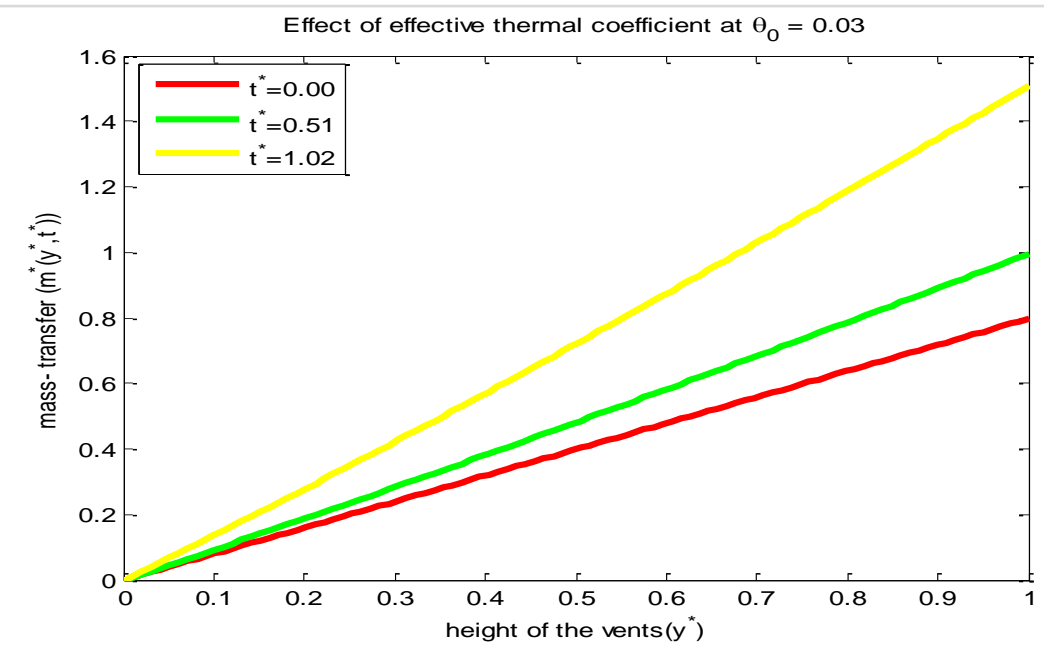

Figure 28 Mass- transfer for different values of $\boldsymbol{t}^{*}\left(\boldsymbol{\theta}_{\mathbf{0}}=0.03, \mathrm{Gr}=20, \boldsymbol{P r}=\mathbf{0 . 7 1 0}\right)$ 


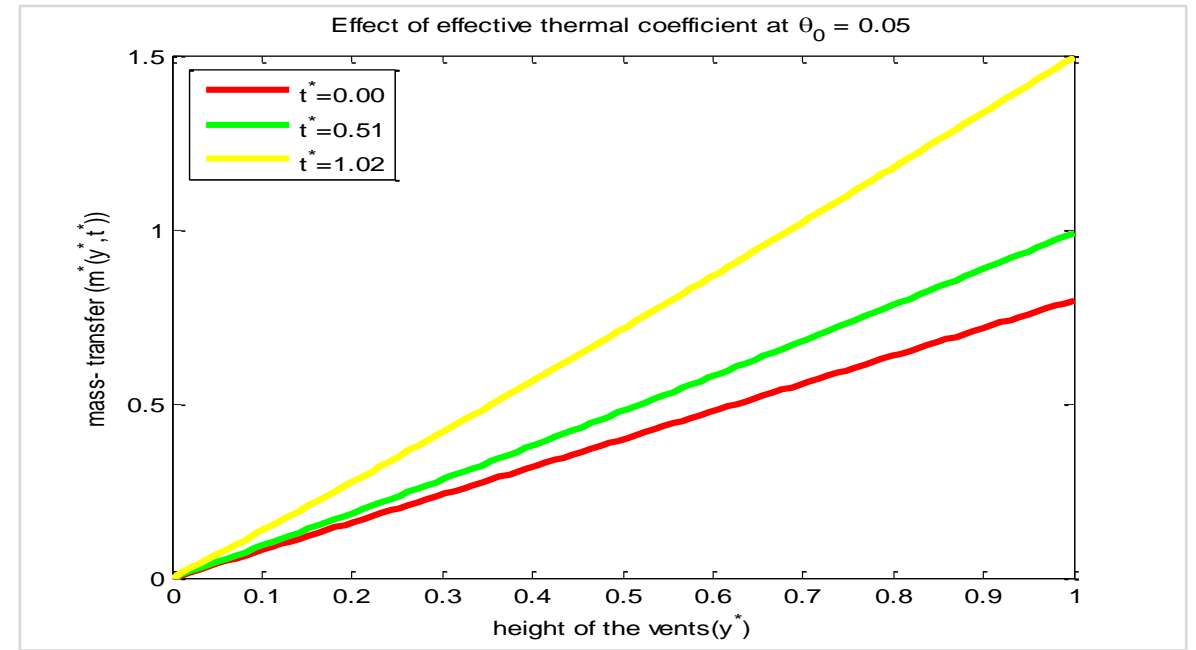

Figure 29 Mass- transfer for different values of $\boldsymbol{t}^{*}\left(\boldsymbol{\theta}_{\mathbf{0}}=0.05, \boldsymbol{G r}=20, \boldsymbol{P r}=\mathbf{0 . 7 1 0}\right)$

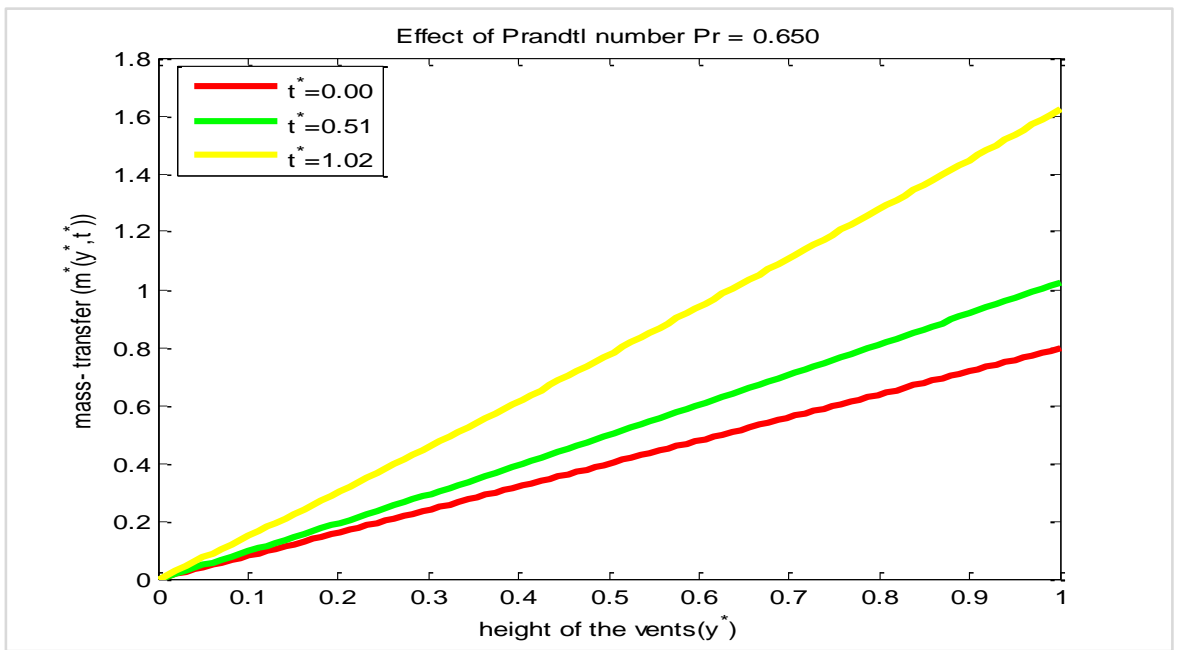

Figure 30 Mass- transfer for different values of $\boldsymbol{t}^{*}\left(\boldsymbol{P r}=\mathbf{0 . 6 5 0}, \boldsymbol{\theta}_{\mathbf{0}}=\mathbf{0 . 0 3}, \boldsymbol{G r}=20\right)$

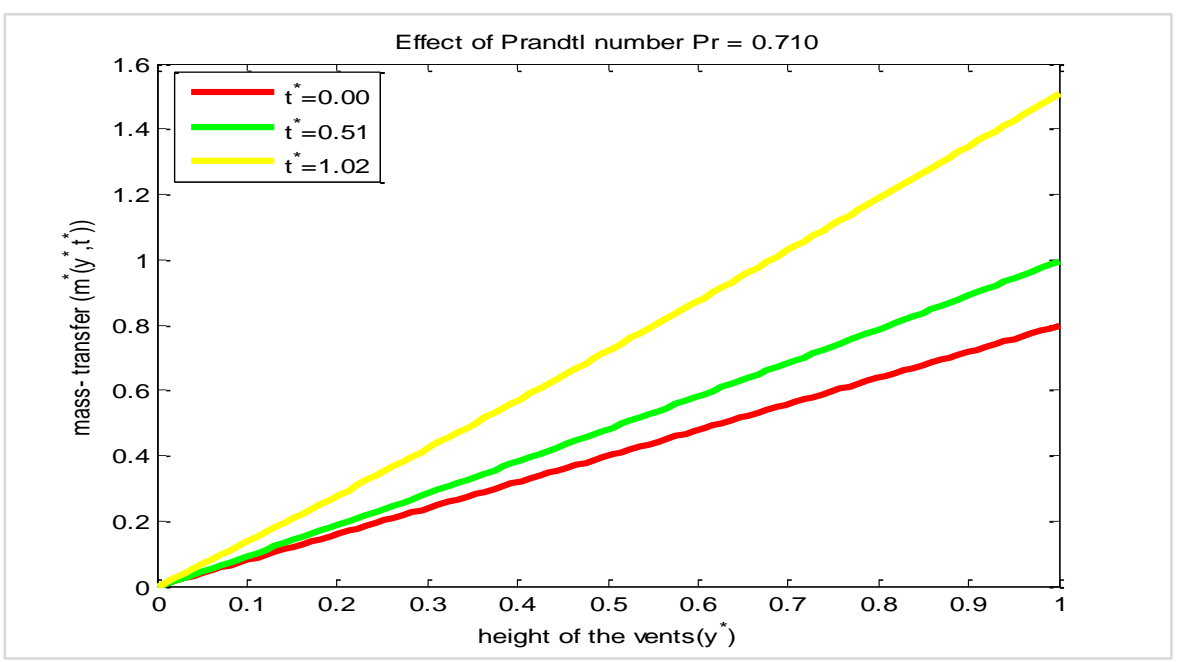

Figure 31 Mass- transfer for different values of $\boldsymbol{t}^{*}\left(\boldsymbol{P r}=\mathbf{0 . 7 1 0}, \boldsymbol{\theta}_{0}=\mathbf{0 . 0 3}, \boldsymbol{G r}=20\right)$

67 
Muhammad Auwal Lawan et al.

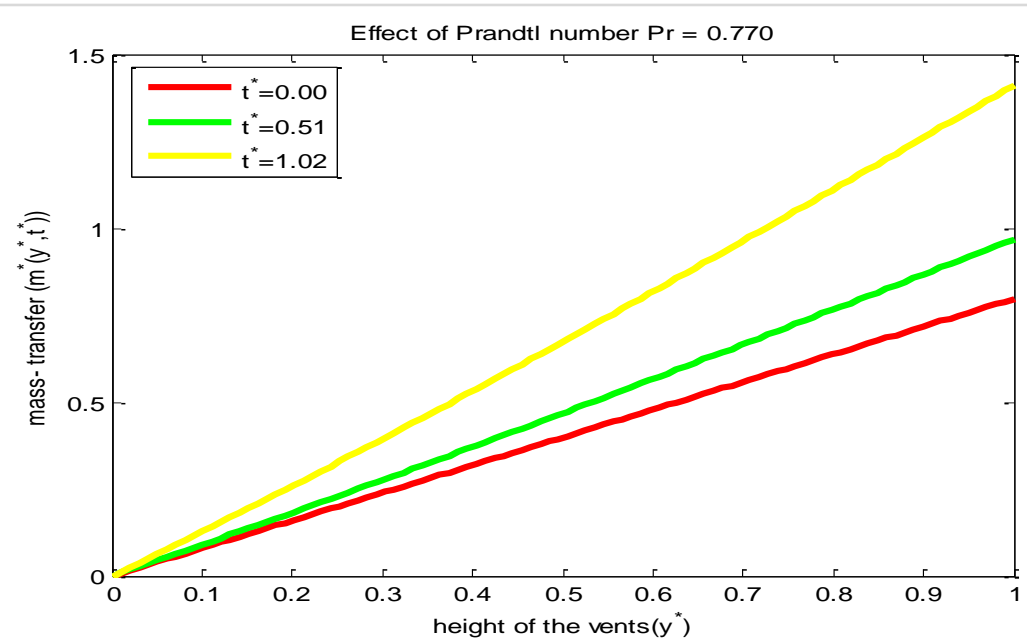

Figure 32 Mass- transfer for different values of $\boldsymbol{t}^{*}\left(\boldsymbol{P r}=\mathbf{0 . 7 7 0}, \boldsymbol{\theta}_{\mathbf{0}}=\mathbf{0 . 0 3}, \mathbf{G r}=20\right)$

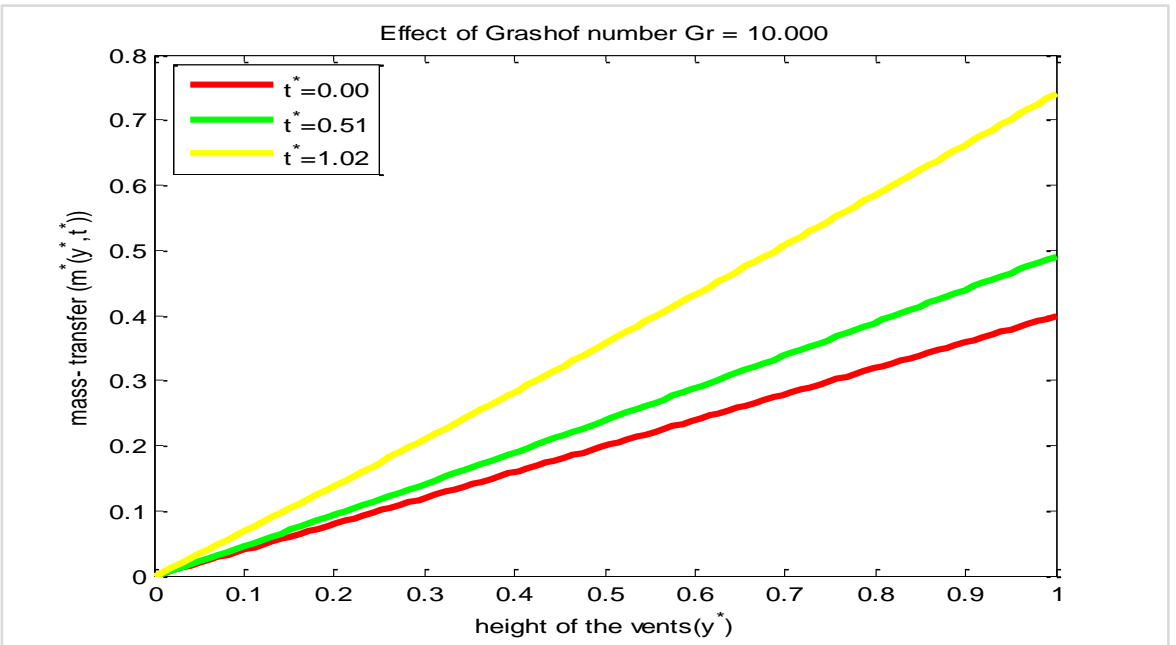

Figure 33 Mass- transfer for different values of $\boldsymbol{t}^{*}\left(\boldsymbol{G r}=\mathbf{1 0}, \boldsymbol{\theta}_{\mathbf{0}}=\mathbf{0 . 0 3}, \operatorname{Pr}=\mathbf{0 . 7 1 0}\right)$

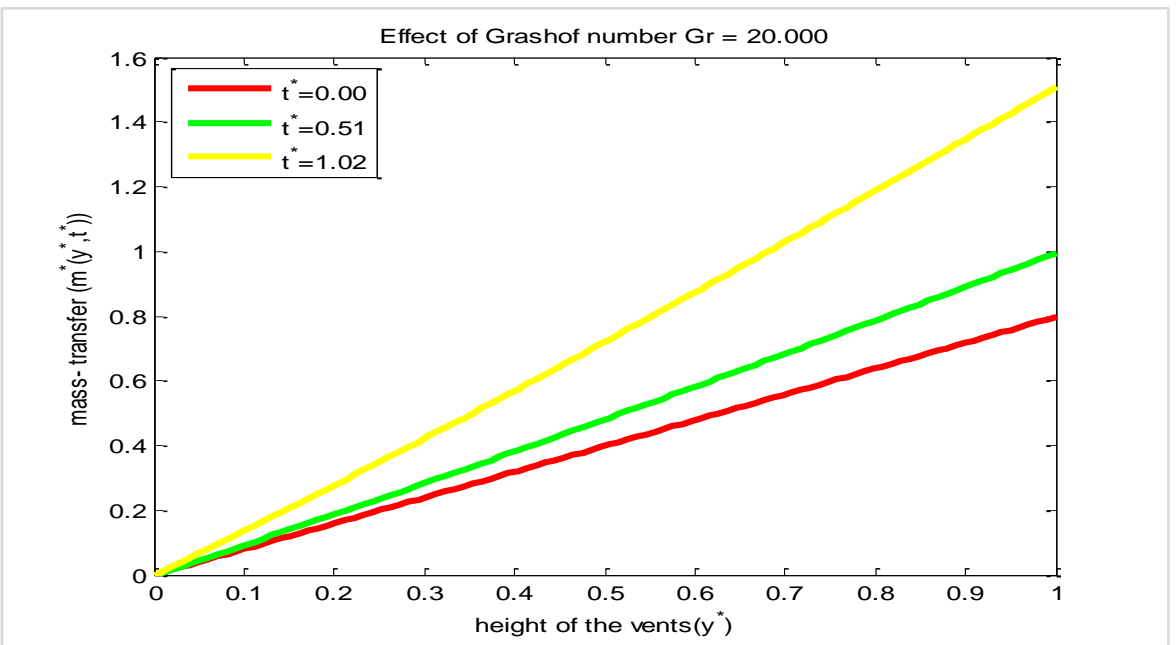

Figure 34 Mass- transfer for different values of $\boldsymbol{t}^{*}\left(\boldsymbol{G r}=\mathbf{2 0}, \boldsymbol{\theta}_{\mathbf{0}}=\mathbf{0 . 0 3}, \operatorname{Pr}=\mathbf{0 . 7 1 0}\right)$ 


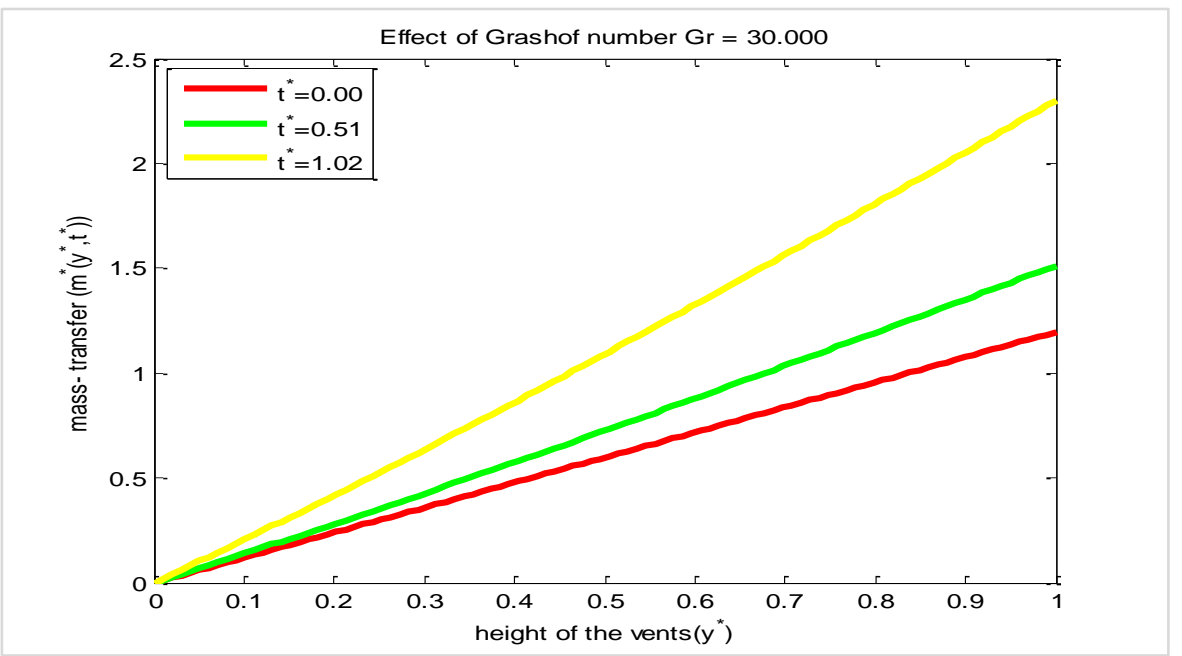

Figure 35 Mass- transfer for different values of $\boldsymbol{t}^{*}\left(\boldsymbol{G r}=\mathbf{3 0}, \boldsymbol{\theta}_{0}=0.03, \boldsymbol{P r}=\mathbf{0 . 7 1 0}\right)$

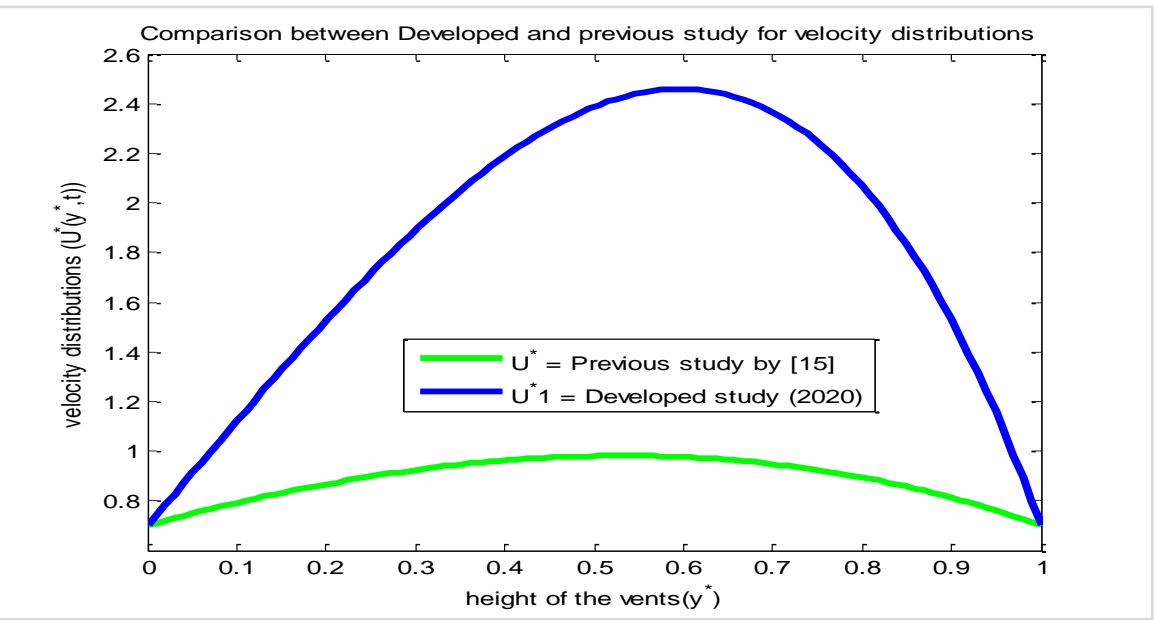

Figure 36 Comparison between velocity profiles $\boldsymbol{U}^{*}$ and $\boldsymbol{U}^{*} \mathbf{1}$ for fixed values of $\boldsymbol{\theta}_{\mathbf{0}}=\mathbf{0}$. 03, $\boldsymbol{P r}=\mathbf{0}$. 710, and Gr $=20$

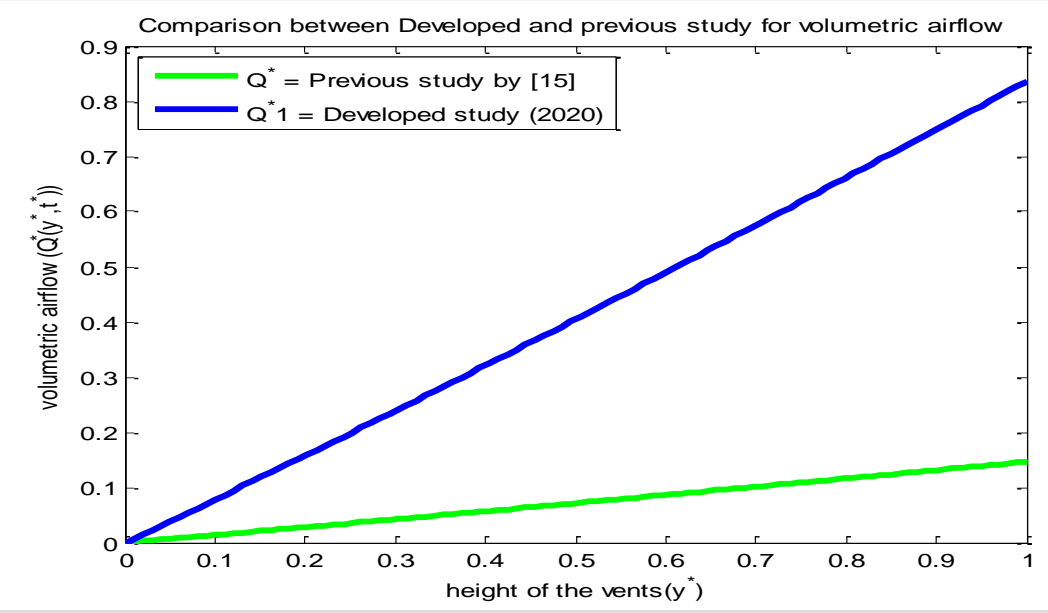

Figure 37 Comparison between volumetric airflow $\boldsymbol{Q}^{*}$ and $\boldsymbol{Q}^{*} \mathbf{1}$ for fixed values of $\boldsymbol{\theta}_{\mathbf{0}}=\mathbf{0 . 0 3}, \boldsymbol{P r}=\mathbf{0 . 7 1 0}$, and $\boldsymbol{G r}=\mathbf{2 0}$ 


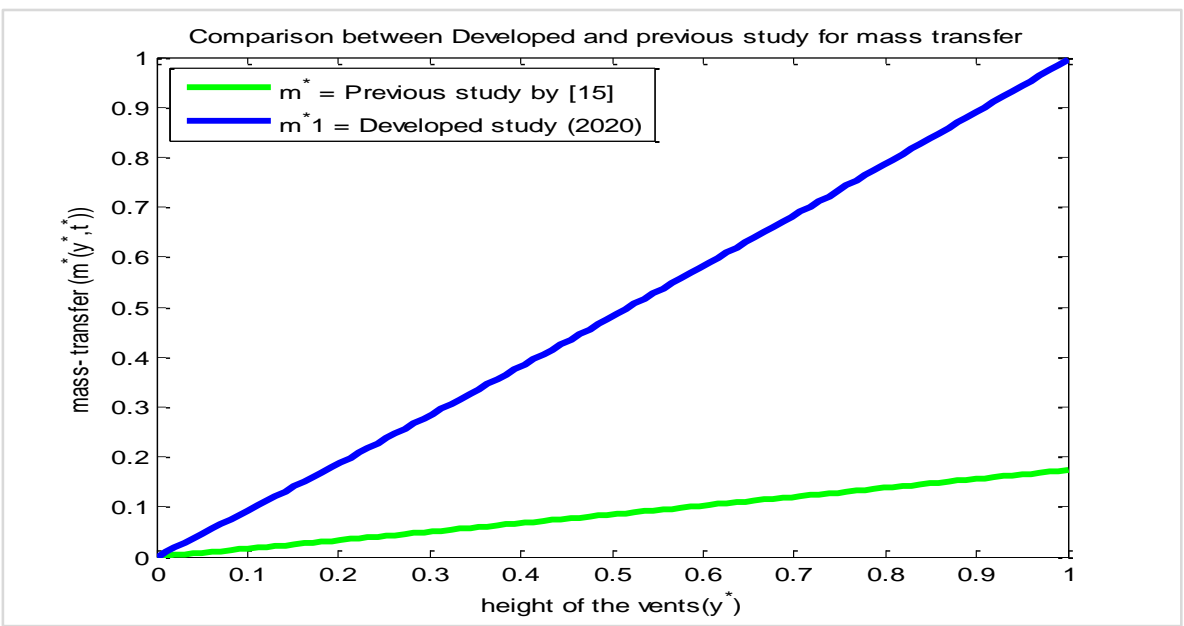

Figure 38: Comparison between mass transfer $\boldsymbol{m}^{*}$ and $\boldsymbol{m}^{*} \mathbf{1}$ for fixed values of $\boldsymbol{\theta}_{\mathbf{0}}=\mathbf{0 . 0 3}, \boldsymbol{P r}=\mathbf{0 . 7 1 0}$, and Gr $=20$

\section{Conclusion}

In this paper, transient effect of constant indirect flow velocity in rectangular building with multiple- upper vents induced by stack- driven effect was studied. The governing equations describing the flow are written in dimensionless form and solved theoretically by means of separation of variable method. The effect of each physical parameter involved in the study is discussed with aid of graphs. It was found that effective thermal coefficient $\left(\theta_{-} 0\right)$, Prandtl number(Pr) and Grashof number(Gr) exerts significant influence on the airflow velocity, temperature distributions together with mass- transfer and volumetric airflow.

The following major conclusions have been achieved from the paper.

1- Temperature increase with an increase of effective thermal coefficient $\left(\theta_{0}\right)$ and Prandtl number $(P r)$.

2- Velocity distributions across the openings increase with an increase of effective thermal coefficient $\left(\theta_{0}\right)$, Prandtl number $(P r)$ and Grashof number $(G r)$.

3- Volumetric airflow increase with an increase of effective thermal coefficient $\left(\theta_{0}\right)$, Prandtl number $(P r)$ and Grashof number $(G r)$.

4- Mass- transfer increase with an increase of effective thermal coefficient $\left(\theta_{0}\right)$, Prandtl number $(\mathrm{Pr})$ and Grashof number $(\mathrm{Gr})$.

5- Present results for velocity distributions, volumetric airflow and mass- transfer goes significantly upward compared with the results for previous intervention given by [15]

\section{Acknowledgment}

None.

\section{Conflicts of interest}

The authors have no conflicts of interest to declare.

\section{References}

[1] Allocca C, Chen Q, Glicksman LR. Design analysis of single-sided natural ventilation. Energy and Buildings. 2003; 35(8):785-95.

[2] Awbi HB, Nemri MM. Scale effect in room airflow studies. Energy and Buildings. 1990; 14(3):207-10.

[3] Awbi HB. Air movement in naturally-ventilated buildings. Renewable Energy. 1996; 8(1-4):241-7.

[4] Chow CL. Air flow rate across vertical opening induced by room heat sources. International Journal on Architectural Science. 2010; 8(1):11-6.

[5] Muhammad AL, Baffa AB, Ringim MZ. Investigations of stack-driven airflow through rectangular cross-ventilated building with two openings using analytic technique. International Journal of Computer Applications. 2016; 141(6):5-11.

[6] Muhammad AL, Gano DA, Ringim MZ, Ibrahim SA, Baffa AB. Theoretical study on steady airflow through multiple upper opennings inside a rectangular building in the presence of indirect flow. Communications on Applied Electronics. 2018; 7(14):17-25.

[7] Duan S, Lia Y. An example of solution multiplicity in a building with bi-directional flow openings. Indoor and Built Environment. 2005; 14(5):359-69.

[8] Fan Y. CFD modelling of the air and contaminant distribution in rooms. Energy and Buildings. 1995; 23(1):33-9.

[9] Gan G. Evaluation of room air distribution systems using computational fluid dynamics. Energy and Buildings. 1995; 23(2):83-93.

[10] Gan G. Simulation of buoyancy-driven natural ventilation of buildings - impact of computational domain. Energy and Buildings. 2010; 42(8):1290-300. 
[11] Murakami S, Kato S. Numerical and experimental study on room airflow-3-D predictions using the k- $\epsilon$ turbulence model. Building and Environment. 1989; 24(1):85-97.

[12] Liddament MW. A review of building air flow simulation. Oscar Faber; 1991.

[13] Gladstone C, Woods A, Philips J, Caulfield C. Experimental study of mixing in a closed room by doorway exchange flow. InProc 1998:555-61.

[14] Linden PF, Lane-Serff GF, Smeed DA. Emptying filling boxes: the fluid mechanics of natural ventilation. Journal of Fluid Mechanics. 1990; 212:309-35.

[15] Muhammad AL, Baffa AB, Dauda UM. Transient airflow process across three vertical vents induced by stack-driven effect inside un-stratified cross-ventilated rectangular building with an opposing flow in one of the upper opening. International Journal of Computer Applications. 2016;148:4-11.

[16] Riahi DN. Mathematical modeling of wind forces. Department of Theoretical and Applied Mechanics (UIUC); 2005.

[17] Spindler HC, Norford LK. Naturally ventilated and mixed-mode buildings - part I: thermal modeling. Building and Environment. 2009; 44(4):736-49.

[18] Hunt GR, Linden PF. Steady-state flows in an enclosure ventilated by buoyancy forces assisted by wind. Journal of Fluid Mechanics. 2001; 426:355-86.

[19] Luo Z, Zhao J, Gao J, He L. Estimating naturalventilation potential considering both thermal comfort and IAQ issues. Building and Environment. 2007; 42(6):2289-98.

[20] Fuliotto R, Cambuli F, Mandas N, Bacchin N, Manara $\mathrm{G}$, Chen Q. Experimental and numerical analysis of heat transfer and airflow on an interactive building facade. Energy and Buildings. 2010; 42(1):23-8.

[21] Santamouris M, Argiriou A, Asimakopoulos D, Klitsikas N, Dounis A. Heat and mass transfer through large openings by natural convection. Energy and Buildings. 1995; 23(1):1-8.

[22] Van Hooff T, Blocken B. CFD evaluation of natural ventilation of indoor environments by the concentration decay method: $\mathrm{CO} 2$ gas dispersion from a semi-enclosed stadium. Building and Environment. 2013; 61:1-17.

[23] Yin W, Zhang G, Yang W, Wang X. Natural ventilation potential model considering solution multiplicity, window opening percentage, air velocity and humidity in China. Building and Environment. 2010; 45(2):338-44.

[24] Wilson DJ, Kiel DE. Gravity driven counterflow through an open door in a sealed room. Building and Environment. 1990; 25(4):379-88.

[25] Wang X, Huang C, Cao W. Mathematical modeling and experimental study on vertical temperature distribution of hybrid ventilation in an atrium building. Energy and Buildings. 2009; 41(9):907-14.

[26] Jiang Y, Chen Q. Buoyancy-driven single-sided natural ventilation in buildings with large openings.
International Journal of Heat and Mass Transfer. 2003; 46(6):973-88.

[27] Zöllner A, Winter ER, Viskanta R. Experimental studies of combined heat transfer in turbulent mixed convection fluid flows in double-skin-facades. International Journal of Heat and Mass Transfer. 2002; 45(22):4401-8.

[28] Li Y, Delsante A, Symons J. Prediction of natural ventilation in buildings with large openings. Building and Environment. 2000; 35(3):191-206.

[29] Li Y, Delsante A. Natural ventilation induced by combined wind and thermal forces. Building and Environment. 2001; 36(1):59-71.

[30] Britter RE, Hunt JC, Mumford JC. The distortion of turbulence by a circular cylinder. Journal of Fluid Mechanics. 1979; 92(2):269-301.

[31] Lo LC. Predicting wind driven cross ventilation in buildings with small openings (Doctoral dissertation).2012. The University of Texas at Austin.

[32] Acred A, Hunt GR. A simplified mathematical approach for modelling stack ventilation in multicompartment buildings. Building and Environment. 2014; 71:121-30.

[33] Balocco C, Colombari M. Thermal behaviour of interactive mechanically ventilated double glazed façade: non-dimensional analysis. Energy and Buildings. 2006; 38(1):1-7.

[34] Cooper P, Linden PF. Natural ventilation of an enclosure containing two buoyancy sources. Journal of Fluid Mechanics. 1996; 311:153-76.

[35] Brown WG, Solvason KR. Natural convection through rectangular openings in partitions-1: vertical partitions. International Journal of Heat and Mass Transfer. 1962; 5(9):859-68.

[36] Brown WG, Solvason KR. Natural convection heat transfer through rectangular openings in partitions-II. International Journal of Heat and Mass Transfer. 1962; 5:869-78.

[37] Linden PF. The fluid mechanics of natural ventilation. Annual Review of Fluid Mechanics. 1999; 31:201-38.

[38] Yang T. CFD and field testing of a naturally ventilated full-scale building. Doctoral dissertation, University of Nottingham. 2004.

[39] Muhammad AL, Ringim MZ, Isma'il LA. Transient investigation of stack-driven airflow process through rectangular cross-ventilated building with two vents in the absence of opposing flow in the upper opening. International Journal of Engineering \& Technology. 2018; 7(3):1249-56.

[40] Raji B, Tenpierik MJ, Bokel R, Van Den Dobbelsteen A. Natural summer ventilation strategies for energysaving in high-rise buildings: a case study in the Netherlands. International Journal of Ventilation. 2020; 19(1):25-48.

[41] Lastovets N, Kosonen R, Mustakallio P, Jokisalo J, Li A. Modelling of room air temperature profile with displacement ventilation. International Journal of Ventilation. 2020; 19(2):112-26.

[42] Koufi L, Younsi Z, Naji H. Computational of the wind velocity effect on infiltration rates in an individual 
building using multi-zone airflow model. International Journal of Ventilation. 2019; 18(1):46-63.

[43] Elghamry R, Hassan H. Impact of window parameters on the building envelope on the thermal comfort, energy consumption and cost and environment. International Journal of Ventilation. 2020; 19(4):23359.

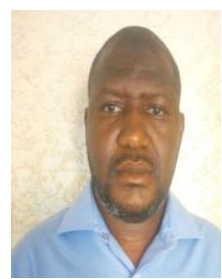

Muhammad Auwal Lawan is a Senior Lecturer at Department of Mathematics, Kano University of Science and Technology Wudil (KUST), Nigeria. He obtained his BSc., MSc., and Ph.D (Mathematics) from Bayero University Kano (BUK), Nigeria. He is a member of Nigerian Mathematical Society (NMS), Mathematics Association of Nigeria (MAN) and Nigerian Association of Mathematical Physics (NAMP). He has published several papers on local, international journals, conferences and book chapters. His research interests include Fluid dynamic on Natural Ventilation in Building.

Email: mukhazah3@gmail.com

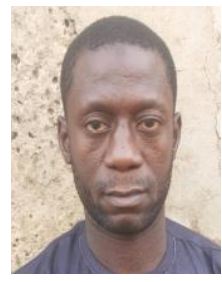

Sunusi Aminu Nata' Ala is an MSc researcher at Department of Mathematics, Kano University of Science and Technology, Wudil (KUST), Nigeria. He obtained his BSc (Mathematics) from Kano University of Science and Technology Wudil (KUST), Nigeria.

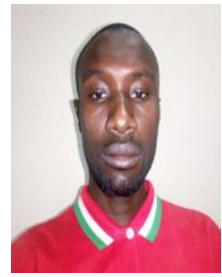

Muhammad Yusuf Muhammad is a Lecturer at Department of Mathematics, Kano University of Science and Technology (KUST), Nigeria. He obtained his BSc (Mathematics), and MSc (Mathematics) from Kano University of Science and Technology Wudil (KUST), Nigeria. He has published several papers on local, international journals and conferences. His research interests include Modeling Water Flow in porous media and also who wish to continue to grow in leadership and knowledge, excel in innovative technology applications, interact and share with team members, colleagues and develop world class solution to the contemporary global challenges.

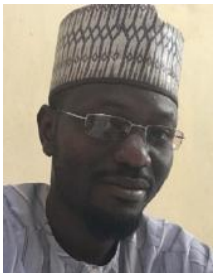

Aliyu Lawan Musa is an MSc researcher at Department of Computer and Control Engineering, Ahmadu Bello University (ABU), Zaria, Nigeria. He obtained his BEng (Computer) from Bayero University Kano (BUK), Nigeria. He is a member of National Council for Regulation of Engineering in Nigeria (COREN). His research interests include Brain Inspired Artificial Intelligence, Neuroscience, Spiking Neural Networks, and Machine Learning Techniques and Applications.

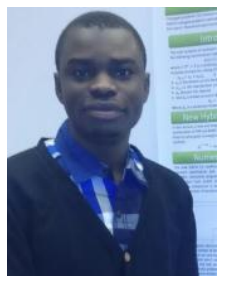

Rabi’ u Bashir Yunusa is a Lecturer at Department of Mathematics, Kano University of Science and Technology (KUST), Nigeria. He obtained his BSc (Mathematics) from University of Science and Technology Wudil (KUST), Nigeria, and MSc (Mathematics) from University Sultan Zainal Abidin (UniSZA), Malaysia. He has published several publications in indexed journals, and conference proceedings. His research interests include Computational Mathematics, and Unconstrained Optimization.

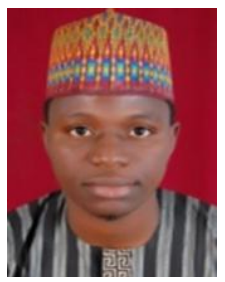

Bashir Danladi Garba is a Lecturer at Department of Mathematics, Kano University of Science and Technology (KUST), Nigeria. He obtained his BSc (Mathematics) from University of Science and Technology Wudil (KUST), Nigeria, and MSc (Mathematics) from Bayero University Kano (BUK), Nigeria. He has published several papers on local, international journals, and conferences. His research interests include Computational Mathematics, Integral and Integro-differential Equations, and Numerical Analysis. 